\title{
THE SCIENCE OF MULTIPLICITIES: POST-STRUCTURALISM AND ECOLOGICAL COMPLEXITIES IN DESIGN
}

By

\author{
Luke Feast
}

A thesis

submitted to the Victoria University of Wellington

in fulfilment of the requirement for the degree of Master of Design

Victoria University of Wellington

2006 


\section{Abstract}

This research investigates the potential contribution of the philosophy of Gilles Deleuze to design research. Through a comprehensive review of the literature an understanding of the themes of immanence and anti-essentialism in naturalism and environmental ethics was generated. Using interpretations of Deleuze's philosophy with the sciences of complexity, I investigate the themes identified through the extension of the notion of self-organising material systems to the socio-technical realm of design research. Through the analysis of architecture and design discourses in the 1990's an immanent field of design research is presented. The implications are drawn out through the investigation of a general ethico-aesthetic theory of design research through the comparison of problematic and axiomatic epistemology. The research concludes by presenting a better understanding of the relationship of issues of the environment and design as well as providing a conceptual framework that can enable productive dialogue between architectural and design discourses. 
I would like to acknowledge Vladimir Mako, Sam Kebbell, and Maxe Fisher for their inspiration, patience, guidance, and encouragement which made this research project enjoyable and rewarding.

I would like to thank my family for their support, and to my friends for making a difference. 


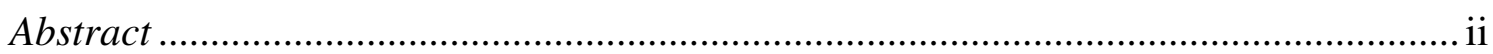

Acknowledgements ...............................................................................................ii

Table of Contents …………………………………………………………………… iv

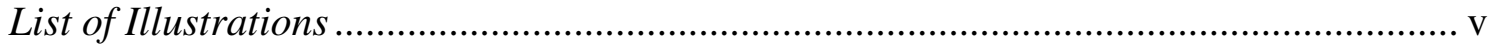

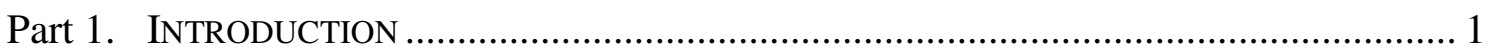

Part 2. LiterAture REVIEW: Post-STRUCtURALISM AND ISSUES OF ENVIRONMENT ..... 3

2.1. Philosophies of Difference: Differentiating Deleuze and Derrida............. 4

2.2. Discourses of the Environment: Foucault ............................................. 16

2.3. Geophilosophy: Deleuze's Radical Naturalism .................................... 28

2.3.1. Deleuze's Philosophy and the Sciences of Complexity................ 29

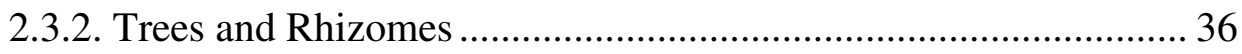

2.3.3. The Body-without-Organs .................................................. 50

2.3.4. Deleuze's Schizoanalytical Method .......................................... 63

Part 3. Argument: DeleuZE AND ECological ThEORIES OF DESIGN ........................ 65

3.1. The Discrete and the Continuous in Architecture and Design ................. 67

3.2. Time in Architecture and Design: Mapping Dynamic Complexity ......... 77

3.3. Conceptualisation: Design Processes and the Science of Multiplicities .. 87

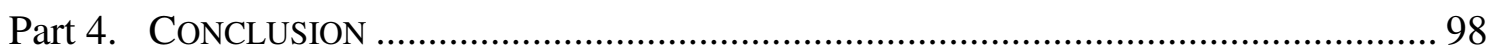

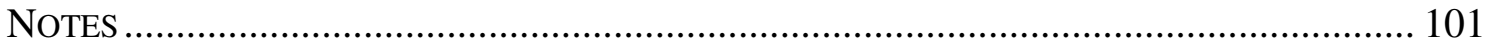

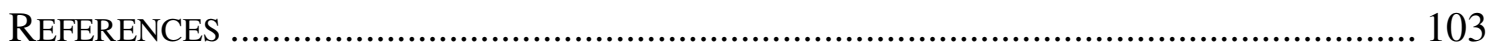




\section{List of Illustrations}

Table 1. Trajectories of Immanence and Transcendence in Continental Philosophy .. 12

Table 2. The Double Articulation of Content and Expression.....................................39

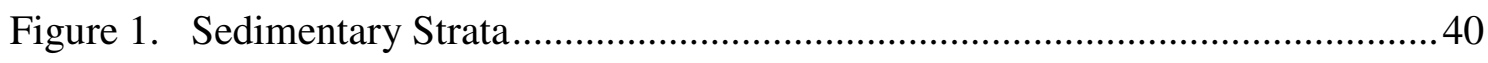

Figure 2. Consistency of Heterogeneous Elements....................................................... 46

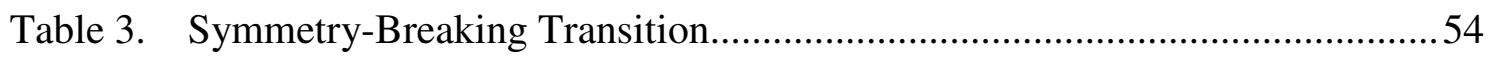

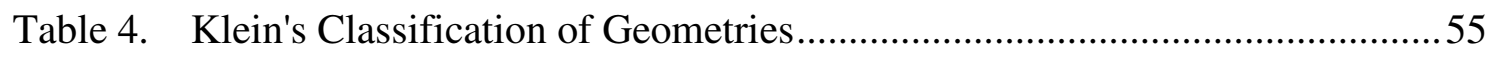

Table 5. Transitions toward a Continuous Diagram of Complexity ...........................67 


\section{Part 1. INTRODUCTION}

This part introduces the research presented in this thesis. It explains the research focus and introduces research themes that the study aims to address, with the conclusions outlined. An overview of the thesis structure is also provided.

The research presented in this thesis sets out to investigate the potential contribution of the philosophy of Gilles Deleuze to design. Through a comprehensive review of the literature an understanding of the themes of immanence and anti-essentialism in naturalism and environmental ethics was generated. Using interpretations of Deleuze's philosophy with the sciences of complexity, I investigate the themes identified in the literature through the analysis of architecture and design discourses in the 1990's. An epistemological shift from a discrete to a continuous model of complexity is identified within the transition from mechanical representation to diagrammatic practice in folded architecture, and from solving clearly defined problems to conceiving scenarios in ecologically sustainable design. Following Deleuze, this transition is conceptualised as a shift from the axiomatic approach of royal science to the problematic approach of minor science and implies an evolution between two different models of the relationship linking matter and form. The hylomorphic model of royal science in which matter is presupposed as a homogenous and inert mass obedient to forms imposed from the outside is contrasted with the artisanal model of minor science which can negotiate matter in non-linear, intensive and complex conditions. This shift in design processes implies an intimate relationship between epistemology and ontology, where the problems posed by humans become isomorphic with the dynamic process of material systems, which enables us to understand the relationship between design and issues of 
the environment in a different way. Deleuze's philosophy is seen to provide a

theoretical framework which can enable conceptual exchange between architecture and design discourses and indicate potential directions for future interdisciplinary research.

The report is intended as a resource for students and researchers in the field of design and is structured in 4 major parts:

1. Introduction: This part introduces the research presented in this thesis. It explains the research focus and introduces research questions that the study aims to address, with the conclusions outlined.

2. Literature Review: This part explores the literature surrounding poststructuralism and the philosophy of Gilles Deleuze, in regard to issues of the environment and naturalism. This part is concerned with establishing the philosophical themes that motivate the research into architecture and design discourses undertaken in the next part.

3. Argument: This part addresses the themes of immanence and anti-essentialism encountered in Deleuze's naturalism, through the analysis of the architecture and design discourses in the 1990's. The immanent field of design research presented is interpreted through the comparison of problematic and axiomatic epistemology.

4. Conclusion: This part draws together the general conclusion for the research presented in this thesis, and reflects on the themes that have been investigated and addressed. It then considers the limitations of the work and makes suggestions for future research. 


\section{Part 2. LITERATURE REVIEW: POST-STRUCTURALISM AND ISSUES OF ENVIRONMENT}

This part reviews the literature surrounding post-structuralism and the philosophy of Gilles Deleuze, in regard to issues of the environment and naturalism. It begins by introducing then differentiating Deleuze's philosophy from the deconstruction of Jacques Derrida. It illustrates how Derrida's concern with a textually framed critique is aligned toward a trajectory of transcendence in contrast with Deleuze's connection with science and commitment to immanence. The identification of the key theme of immanence, in turn aligns Deleuze's philosophy with that of Michel Foucault. Through Foucault's genealogy of life as an object of discourse, I determine the significant issue of essentialism in naturalism and environmental ethics. Finally, this part examines the intersection of Deleuze's geophilosophy with the sciences of complexity, which I determine provides a philosophical naturalism consistent with a trajectory of immanence and Foucault's critique of essentialism. The literature review identifies the themes of immanence and anti-essentialism that will be addressed in the third part of this research project in regard to architecture and design discourses in the 1990's, in order to further the understanding of the potential of the philosophy of Gilles Deleuze for design research. 


\subsection{Philosophies of Difference: Differentiating Deleuze and Derrida}

The series of publications in the late 1960s by Gilles Deleuze and Jacques Derrida contributed to the emergence of what has become known as post-structuralist philosophy. Through their analysis of the concept of difference, both Deleuze and Derrida ask what it is to "think" difference in itself, a concept of difference that is irreducible to identity, which destabilizes dialectical opposition and opens the way for a new critique of philosophy. Gilles Deleuze (1925-1995) and Jacques Derrida (19302004) completed their education in Paris, at the Sorbonne and the Ecole Normal Superieur respectively, and developed their philosophies of difference within the same post WWII French intellectual climate. To some extent it can be said that they both belong to the same generation which came of age in the creative and tumultuous 1960s French intellectual scene, which also includes Michel Foucault (1926-1984), Louis Althusser (1918-1990), Jean-François Lyotard (1924-1998), and Michel Serres (1930- ) among others.

\section{Affinities and Divergences}

Both Deleuze and Derrida made their first important contributions to the French scene in the 1960s: Deleuze with Nietzsche and Philosophy (1962) which is credited with sparking the French revival of Nietzschean studies, and then in 1968 with his magnum opus and doctoral dissertation Difference and Repetition and accompanying thesis Expressionism in Philosophy: Spinoza. Jacques Derrida published three significant books in 1967, Writing and Difference, Of Grammatology and Speech and Phenomena, which after their translation into English in the 1970s, led deconstruction to becoming one of the most important intellectual movements in literary theory and throughout much of the humanities and social sciences in the $20^{\text {th }}$ century. Derrida (1995/2001) wrote in his 1995 eulogy for Deleuze, I'm Going to Have to Wander All 
Alone, that he felt "near total affinity" between his work and Deleuze's, at least at the level of "theses" while acknowledging the "very obvious distances in what I would call - lacking any better term - the 'gesture', the 'strategy', and 'manner': of writing, of reading, and speaking perhaps" (p. 192). Even though there are differences in their writing styles, there are parallels in the way each negotiated the institutionalised history of philosophy by inhabiting canonical tests in order to transform or deform the thought in question. In response to their belonging to a generation that in Deleuze's (1995) words "was more or less bludgeoned to death with the history of philosophy" (p. 5), Deleuze (1977), considered his approach "as a kind of buggery, or, what amounts to the same thing, an immaculate conception. I imagined myself approaching the author from behind and giving him a child that would be his but nonetheless, monstrous" (para. 4). In other words, Deleuze extracts arguments and concepts from the history of philosophy and then transposes them, still fully functional, in a new and disruptive site. Derrida's own relation to the history of philosophy is of course one of the most remarkable aspects of his work. As Patton and Protevi explain,

Although he began his career by positing the deconstructive intervention into the great texts of the Western tradition as aiming at the difference between the author's intention and the performance of the text, he quickly moved to pinpointing the location of the deconstructive lever between readings of the ways in which a productive difference had always already constituted the longed-for presence. $(2003$, p. 3)

In this insistence in destabilising and undermining the repressive powers within the texts of the history of philosophy, we can see one of the clearest affinities between Deleuze and Derrida.

In his eulogy for Deleuze, Derrida (1995/2001) listed among their most notable points of agreement "the [thesis] concerning an irreducible difference that is in opposition to dialectical opposition, a difference "more profound" than a contradiction (Difference and Repetition), a difference in the joyously repeated affirmation ("yes, yes"), a taking into account of the simulacrum" (pp. 192-193). Although investigated in 
different contexts, both Deleuze and Derrida were concerned with the development of a non-Hegelian philosophy of difference which affirmed a non-dialectical concept of difference that is irreducible to identity, and which served to complicate philosophical prejudice in favour of unity, closure and homogeneity over diversity, openness and heterogeneity.

Despite their resonances, the philosophical projects of Deleuze and Derrida do follow divergent trajectories, beginning first and foremost with their different philosophical allegiances. Hegel, Husserl and Heidegger are important to Derrida in ways that they are not to Deleuze. Derrida devoted the first 15 years of his career to the study of Husserl and the centrality of Heidegger to his deconstruction of metaphysics is evident throughout his writing since then. While it could be overly simplified to say that Derrida's notion of difference is essentially post-phenomenological, and Deleuze's notion of difference is material and forceful, this characterisation does reflect real differences in their sources and philosophical orientations. Heidegger's thought on the history of metaphysics is much more important to Derrida than for Deleuze (1995), who once said that "I've never worried about going beyond metaphysics or the death of philosophy, and I never made a big deal out of giving up Totality, unity, the Subject" (p. 136). While Derrida always takes phenomenology as his point of departure, even as he relentlessly shows its limitations, Deleuze never really takes it seriously especially in his later collaborative works with the radical activist and psychoanalyst Felix Guattari (1930 -1992). As Bonta and Protevi relate, $(2004$, p. 7) this position does not mean that Deleuze would not acknowledge fundamental structures in what he calls State philosophy, he merely wants to highlight the arbitrary nature of the Heideggerian and Derridean canons. Derrida's careful meditation on the history of philosophy is also in contrast to Deleuze's “innocent” glee in doing philosophy afresh. 
Deleuze found the raw materials for his own creation of concepts in a philosophical lineage which included Lucretius, Spinoza, Hume, Nietzsche and Bergson. In all these thinkers he discerned a "secret link" formed by "their critique of negativity, their cultivation of joy, their hatred of interiority, the externality of force and relations, the denunciation of power" (Deleuze, 1977, para. 4). These figures are largely absent in Heidegger, and with the exception of Nietzsche, they are rarely discussed by Derrida.

As well as the stylistic and intellectual differences between Deleuze and Derrida, we can also point to the differential reception of their work in the Anglophone world. Neither Derrida nor Deleuze first became known through the discipline of philosophy; instead both entered the English speaking academic world via other avenues of the humanities such as literary studies, art history and theory, film studies and architecture. Only secondarily has their work begun to have an impact in philosophy and the social sciences. While they both took the same "detour" in their reception in the Anglophone philosophical world, the rhythms of translation of their work has been quite different. Derrida's works published in the late 60s, Writing and Difference, Of Grammatology, Speech and Phenomena, and those in the early 70s, Dissemination and Margins of Philosophy (both in 1972) and then Glas (1974), were all translated into English within 7 and 10 years, and since the 80 s the gap shrunk to virtual simultaneity. In contrast, while translations of Deleuze's collaborative works with Guattari were fairly rapid to appear, Anti-Oedipus (1972 trans. 1977) and A Thousand Plateaus (1980 trans. 1987), however, translations of his major individual works Logic of Sense (1969) and Difference and Repetition (1968) took 21 and 26 years respectively, and his early historical works on Nietzsche, Spinoza and Bergson all took over 20 years as well. Thus it was not until the mid 90s that a reasonably complete corpus of Deleuze's works was available in English, a good 15-20 years after Derrida had become a staple of 
Anglophone Continental philosophy. The same gap occurs with the secondary scholarship, with Derrida's work peaking in the mid 80s, and with Deleuze only becoming seriously studied in the mid-late 90 s.

Because neither wrote about each others work directly (with the exception of a few footnotes here and there and Derrida's eulogy) the affinities and divergences between Derrida and Deleuze have only begun to be worked out in the secondary literature (e.g. Holland, 1999; Paton, 2001; Patton \& Protevi, 2003). It is also a fact that the generation of philosophers which Deleuze and Derrida are associated, the soixanthuitards, are no longer so popular in France and consequently their differences are being considered mainly in the Anglophone world and often not in disciplines of philosophy. To further investigate the affinities between Derrida and Deleuze we can consider their respective concepts of différence and repetition.

\section{Différance and Repetition}

The aim of Difference and Repetition, arguably Deleuze's most important contribution to post-structuralist philosophy, is to affirm difference in relation to identity. Developing arguments from mathematics and science as well as philosophy Deleuze (1968/2004a) argues that "The primacy of identity... defines the world of representation. But modern thought is born of the failure of representation, of the loss of identities, and of the discovery of all the forces beneath the representation of the identical" (p. xvii). Deleuze develops arguments extended from Nietzsche and Spinoza that identity must be conceived as subordinate to difference and multiplicity, rather than the other way round.

Such a condition can be satisfied only at the price of a general categorical reversal according to which being is said of becoming, identity of that which is different, the one of the multiple, etc. That identity not be first, that it exist as a principle but as a second principle; ... that it revolve around the Different; such would be the nature of a Copernican revolution which opens up the possibility of difference having its own concept, rather than being maintained under the domination of a concept in general already understood as identical. (1968/2004a, p. 50) 
According to Holland (1999, p. 150), the implication of this reversal transforms the related concept of repetition, for such a reversal introduces difference and divergence into what we understand as repetition. Repetition must now be understood as involving, not identity or equivalence among terms, but difference and variation. Consequently mechanical, or as Deleuze specifies, bare repetition - repetition of the same - must be distinguished from authentic and creative repetition, or repetition of the different. For Deleuze difference in itself and creative repetition are what is given and representation or ideal Forms are merely an effect or illusion. Deleuze (1968/2004a) argues that creative repetition "presupposes a swarm of differences, a pluralism of free, wild or untamed differences, a properly differential and original space and time; all of which persist along-side the simplifications of limitation and opposition" (p. 164).

Difference in itself and creative repetition are concepts which insist upon an image of thought which includes and affirms rather than excludes and negates. As Michel Foucault argues in his review essay on Deleuze's Difference and Repetition and Logic of Sense entitled 'Theatrum Philosophicum',

The freeing of difference requires thought without contradiction, without dialectics, without negation; thought that accepts divergence; affirmative thought whose instrument is disjunction; thought of the multiple - of the nomadic and dispersed multiplicity that is not limited or confined by the constraints of the same. $(1970 / 2002 c$, p. 358)

Derrida's thought also seeks to undermine Hegelian dialectical thinking, for which the history of philosophy is seen from the viewpoint of Absolute Reason and which in turn can trace the evolution of its own triumphant progress to the point where its entire past history is ideally understandable in the light of its present knowledge. In this sense, according to Derrida, Hegelian dialectics forms a meta-narrative which claims to speak the history of truth as well as the truth of history which transcends all previous philosophies by showing how their various problems or antimonies are always finally resolved through the famous triad: thesis, antithesis, synthesis. The key point, 
suggests Derrida, is that Hegel insists that language carries within itself the ability to retrieve past meanings and intentions. For Derrida this means that Hegel's dialectic relies on the presence in language of essential truths which allow our access to past meanings. Derrida's project aims to show how this cannot be the case, and that language does not possess such a presence of truth.

Derrida's critique begins with his understanding of difference. Focussing on language, Derrida coined the neologism différance to suggest how meaning is at once differential and deferred, such that meaning becomes a product of a restless play within language that cannot be fixed or pinned down by definition (Norris, 1987, p. 15). Structuralism, which was the dominant linguistic theory at the time, and the focus of much of Derrida's critique, was underpinned by the view that signs don't have a meaning in and of themselves, but by virtue of their occupying a distinctive place within the systematic network of contrasts and differences which make up any given language. This situation is complicated, according to Derrida (1982/1972, pp. 3-27), by the fact that meaning is nowhere actually present in language but that it is always subject to a kind of semantic slippage (or deferral) which prevents the sign from ever coinciding with itself in a moment of perfect, remainderless grasp. Consequently, the idea behind the neologism is that différance should function not as a static concept, not as a word whose meaning is finally booked into the present, but as one set of marks in a signifying chain which exceeds and disturbs the classical economy of language and representation.

In Derrida's view, the meaning of a word is unstable and depends upon a repetition which both subverts and serves representation. His famous statement that "there is nothing outside of the text" (Derrida, 1967/1976, p. 158) is part of an argument that every text contains an infinite number of texts, an effect produced by both the reader and the text itself. Consequently the privilege of the original over the copy is 
undermined, and that what remains are no longer copies nor originals, but copies of copies without example, simulacra or in Derrida's terms phantasmata.

For Deleuze, like Derrida, art does not imitate but repeats by creation, and so has the nature of simulations not copies. He argues that art affirms difference and undermines representation since it forces movement on the viewer with the effect of opening up a "plurality of centres, a superposition of perspectives, a tangle of points of view, a coexistence of moments" (Deleuze, 1968/2004a, p. 56). This critique of representation can be clearly seen in the serial art of Andy Warhol from the same 1960s period. His endless reproduction and repetition of media-reflexive images breaks apart the bond between model and copy and so opens new space for the simulacrum's proliferation. Any notion of "original" is constantly deferred based on the repetition of such works and their eternal return. Warhol's work renders the standard, stereotyped and repeated intensely perceptible. His art, as Deleuze (1968/2004a) defines simulacra, is "not simple imitation but the act by which the very idea of a model or a privileged position is overturned" (p. 69).

Repetition when understood not as the reiteration of the same but as a creative and dynamic process overcomes the illusion of representation and becomes a point where past and future come together; the eternal return which affirms difference rather than the monotony inherent in mechanical repetition of the same. The productive use of repetition has profound consequence for the privilege historically accorded to originality, identity and representation in art, architecture and design. Approaching repetition as a creative process enables us to examine the notion of object as no longer defined by an essential form, in the face of a world where technology has taken the production and proliferation of images and objects to new speeds and intensities.

Deleuze's project of thinking difference in itself and Derrida's deconstruction of logocentrism, have each put into question the traditional representational concept of 
thought. Derrida and Deleuze both propose that representation is an effect that is produced by difference and repetition, and instead advocate the affirmation of differences, the critique of totalitarianisms, and creative experimentation of singularities. Their revision of identity and language has had profound consequences across many aspects of contemporary society, challenging the underpinning assumptions of traditional philosophy and culture.

\section{Immanence and Transcendence}

To further examine the affinities and divergences between Derrida and Deleuze we can consider their positions in respect to immanence and transcendence. In a recent essay, Giorgio Agamben (1999, p. 239) identified two trajectories in French philosophy both of which pass through Heidegger. First, a trajectory of transcendence beginning with Husserl and Kant and connecting with Levinas and Derrida, and second a trajectory that begins with Spinoza and Nietzsche and continuing to Foucault and Deleuze.

Although Agamben does not develop this typology to the end, it can be a useful map for investigating the divergences between Derrida and Deleuze. Immanence and transcendence are highly over determined terms in the history of philosophy and the development of such a binary opposition may also seem awkward as both Deleuze and Derrida often take binary oppositions as the target of their criticisms. Therefore it may be more useful to consider trajectories of immanence and transcendence rather than positions.

Table 1

Trajectories of Immanence and Transcendence in Continental Philosophy

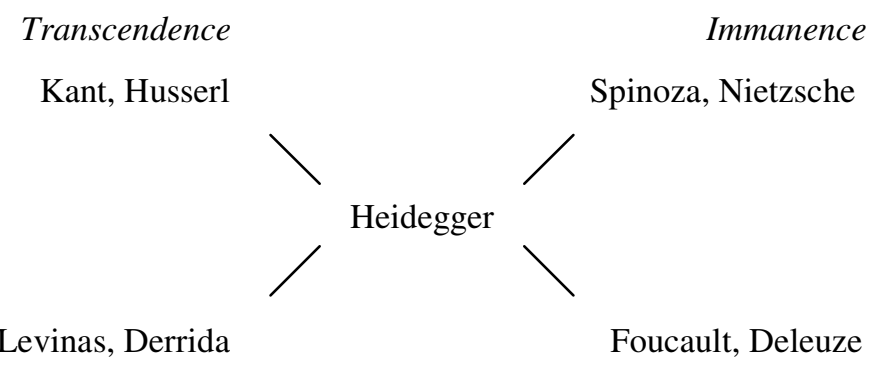


Immanence and transcendence are traditionally found in ontology, epistemology and subjectivity. Derrida and Deleuze each write about these aspects of philosophy, and according to Smith (2003a, p. 47) in each aspect we can see how Derrida aligns himself with transcendence and Deleuze with immanence, however it is in terms of their respective considerations of ontology that, for our purposes, we can most clearly see their philosophical divergence. Ontology is the branch of philosophy that is concerned with the nature of Being. In an immanent ontology, there is nothing beyond, or above or otherwise to being like Plato's Forms or God in the Christian tradition, which are then used to judge or account for being. Deleuze and Derrida, like most contemporary continental philosophers are indebted to Heidegger who brought the question of Being back into $20^{\text {th }}$ century thought (which is why he is placed in the middle of Agamben's typology). Yet it is also clear the Derrida and Deleuze take Heidegger in different directions.

Deleuze develops an immanent and realist ontology, meaning that while he argues that there is nothing transcendent to being, and the set of entities that he is committed to assert that actually exist in reality are fully independent of the human mind disregarding the difference between the observable and the unobservable and the anthropocentrism this implies. This fact clearly distinguishes Deleuze's philosophy from most other postmodern philosophies which are basically anti-realist (DeLanda, 2002a, p. 2). Deleuze's commitment to immanence means that the identity of the objects of the world can not be guaranteed by the possession of an essence, such as Plato's Forms or any other transcendent entity (someone who believes that God exists independent of our minds can also be a realist but this is clearly also transcendental). Deleuze's commitment to immanence and realism means that something else is needed to account for the identity of objects and also what preserves that identity through time; briefly, for Deleuze these are dynamic productive processes. ${ }^{1}$ Deleuze accounts for this through a productive 
engagement with what are today called the Sciences of Complexity, one of the most

innovative and urgent aspects of his philosophy. The ability for Deleuze's philosophy to engage with the material world of matter and energy shows a critical distinction between Deleuze and Derrida, and which aligns Deleuze with Foucault's philosophy of corporeality.

Deleuze is sceptical when it comes to deconstruction's thematic of signification and interpretation. In response to a question about Heidegger and deconstruction posed to him at the 1972 Cerisy colloquium on Nietzsche, Deleuze responds:

If I understand you, you say that there is some suspicion on my part of the Heideggerian point of view. I'm delighted. With regard to the method of deconstruction of texts, I see well what it is, I admire it greatly, but I don't see it as having anything to do with my own. I never present myself as a commentator on texts. A text, for me, is only a little cog in an extra-textual practice. It is not a question of commenting on the text by a method of deconstruction, or by any other method; it is a question of seeing what use a text is in the extra-textual practice that prolongs the text. (Deleuze quoted in Patton \& Protevi, 2003, p. 161)

Derrida remains much more faithful to Heidegger, such that his deconstruction necessarily operates on the basis of a formal structure of transcendence upon which his task of overcoming metaphysics relies. Derrida defines différance transcendentally as originary difference that is beyond being. For Derrida, being is something to be interrogated in the canonical texts of the history of metaphysics. According to Protevi,

While deconstruction can dismantle the presence-form nexus at the heart of the metaphysical representation ... it can't offer us an empirical research program [for exploring material bodies]. In other words, the powerful and to-be-prized effect of deconstruction - the opening out of phenomenological interiority in the form of consciousness to a world of 'force and signification' - is only the highlighting of the dismantling effects of such a world on pretensions to natural or rational identity and stability; deconstruction is unable to articulate the material processes of production of forceful bodies ... deconstruction is top-down [transcendent]: starting with claims of bodies politic to natural and simple identity it shows différance or its cousins worrying and shaking those pretensions ... while Deleuzean historical-libidinal materialism is bottom-up [immanent]: starting with a virtual differential field it investigates the triggers and patterns of the production of bodies politic and thus offers avenues for nuanced pragmatic intervention and experimental production. (2001, p. 4-5) 
Deleuze and Derrida can be seen to belong to the same generation of philosophers who made important contributions to post-structuralism, beginning in the late 1960's, with their critiques of the representational image of thought through their respective concerns with the development of a non-dialectical concept of difference. However, we can differentiate the philosophical projects of Deleuze and Derrida by following their relation to trajectories of immanence and transcendence. While Derrida's deconstructive method carefully exposes philosophical prejudices towards presence and identity, its textural focus necessarily relies upon a transcendent structure even while persistently showing its limitations. In contrast, Deleuze's commitment to a realist ontology and the productive power of material processes, on one hand, distances his philosophy from the linguistic concerns of post-modernism and deconstruction, and on the other, enables greater interaction with science (while remaining critical of science), aligning his work with a trajectory of immanence. While we cannot fault Derrida for not engaging with science in a similar manner as Deleuze, in relation to this research, the arguably more empirical concerns of industrial design and its relation to issues of the environment, suggests that Deleuze's pragmatic approach is more appropriate.

As this research is ultimately concerned with the philosophy of Deleuze, the divergence of Derrida along a trajectory of transcendence means that conscequently I will not specifically examine issues of the environment in deconstruction. In chapter 2.2., I will follow this trajectory of immanence which, according to Agamben's typology (Table 1), aligns Deleuze's work more closely with that of Foucault, and examine Foucault's historical analysis of the contextuality of knowledge and the genealogy of bio-power - discourses concerned with the management and control of life itself. 


\subsection{Discourses of the Environment: Foucault}

Contemporary design discourses, like politics and social theory today, are powerfully influenced by the concepts and practices of the Green movement and of post-structuralist philosophy. Initially however, it would appear that these are movements that are fundamentally in opposition. As suggested by Levy (1999, p. 203), the Green movement has often staged its critique of contemporary social formations in the name of a pure, untouched concept of nature which stands as the goal towards which we should move. Post-structuralist philosophy, conversely, has been profoundly antinaturalistic, because of naturalism being taken as the equivalent to essentialism. For example the following remarks of Michel Foucault,

Naturalism refers, I believe, to two things. A certain theory, the idea that under power with its acts of violence and artifice, we should be able to rediscover the things themselves in their primitive vivacity... And also a certain aesthetic and moral choice: power is bad, ugly, poor, sterile, monotonous and dead; and what power is exercised upon is right, good, and rich. (1988a, pp. 119-120)

This definition of naturalism holds that not only is there is a "dualism of absolute essence and incidental appearance, but also that what is essential is intrinsically more valuable morally and aesthetically" (Foucault, 1988a, pp. 119-120). For Foucault, the claim of any discourse or practice as natural is seen as an ideological move aimed at legitimising particular historical and therefore contingent social relations (Levy, 1999, p. 203). From the perspective of the Green movement, post-structuralism appears as dangerous and anarchic, absorbed in speculative arguments while the forests of the real world are being destroyed. This position which holds that post-structuralism is relativist or nihilist is supported in green design discourses by Victor Papanek (1995) who argues that the "the trivial productions of Post-Modernism and Deconstruction" ... "turns us against our own past and against nature" such that we have forsaken the "spiritual" in design and "abandoned bliss" (p. 11, 51). To the post-structuralists on the other hand, 
these statements appear hopelessly romantic and backward-looking in its call for us to return to some primitive state of harmony with nature (Levy, 1999, p.203).

While the discourses of the environmental movement and of post-structuralist philosophy appear to be in irreconcilable conflict there remains a certain similarity at least at the level of the criticism of humanism. Post-structuralism develops out of a critique of humanist thought, thus apparently resonating with the deep ecological push for a move beyond anthropocentric positions, however this does not lead to a convergence in the solutions they produce (Levy, 1999, p. 204). If post-structuralism rejects man as the meaning-giving centre of thought, it is not in order to replace him with the biosphere or any other non-human substratum or system. What decentres man are the systems of codes which govern a particular culture's language, techniques, values, practices and so forth at a particular time (Levy, 1999, p. 205).

Michel Foucault (1928-1984) was a philosopher and historian whose work reshaped the varied disciplines of history, philosophy, politics, literary theory, social science and art. Foucault sought the conditions of possibility of knowledge, the rules which governed the putting together of statements, and the ruptures in formations where novelty could appear (1969/2002a, pp. 3-15). Foucault's (1982/2002b) objective has been to create "a history of the different modes by which in our culture, human beings are made subjects" (p. 326). There has generally been recourse to observe three periods in Foucault's oeuvre, corresponding to truth, power and ethics, however each period can be seen as part of an investigation into the production of subjectivity (Negri, 2004,

Answer 1, para. 3).

\section{The Archaeology of Epistèmes: The Entry of Life into History}

Things being as they are, nothing has, up to the present, proved that we could define a strategy exterior to [the obligation of truth]. It is indeed in this field of obligation to truth that we can sometimes avoid in one way or another the effects of a domination, linked to structures of truth or to institutions charged with truth. To say these things very schematically, we can find many examples: there has been an ecological movement - which is furthermore very ancient and is not only 
a twentieth century phenomenon - which has often been, in one sense, in hostile relationship with science or at least with a technology guaranteed in terms of truth. But in fact, ecology also spoke a language of truth. It was in the name of knowledge concerning nature, the equilibrium of processes of living things, and so forth, that one could level the criticism. We escaped then a domination of truth, not by playing a game that was a complete stranger to the game of truth, but in playing it otherwise.

Michel Foucault (1988b, p. 15)

The early period of Foucault's work includes books published in the 1960s which were concerned with how scientific discourse and knowledge in general are organised and justified. Foucault named his approach for the research into the structure of knowledge the archaeology of épistèmes, and follows in the French structuralist tradition of history and philosophy of science, represented for example by Gaston Bachelard and Georges Canguilhem. ${ }^{2}$ His method is called archaeological because it attempts to excavate the layers of historical texts in order to uncover what constitutes, or constituted knowledge within a historically specific period. Foucault understood an épistème as a system of possible discourse which comes to dominate an historical era, and which he described as

The total set of relations that unite, at a given period, the discursive practices that give rise to epistemological figures, sciences and possible systems... The épistème is not a form of knowledge or a type of rationality which crossing the boundaries of the most varied of sciences, manifest the sovereign unity of a subject, a spirit, or a period; it is the totality of relations that can be discovered, for a given period between the sciences when one analyses them at the level of discursive regularities. (1969/2002a, p. 211)

According to Foucault (1969/2002a) an épistème is not a "system of postulates that governs all the branches of knowledge," but is rather, "a constantly moving set of articulations, shifts and coincidences that are established only to give rise to others" (p. 211). Foucault's archaeology builds its analyses by adopting the statements of presumed objective reality, the truth-claims of the épistème themselves, as the background of his case studies. Foucault (1969/2002a) insists that archaeology does not try to describe the "thoughts, representations, images, themes, preoccupations that are concealed or revealed in discourses; but those discourses themselves, those discourses as practices 
obeying certain rules" (p. 155). Foucault's research during his archaeological period was situated on scientific discourses and in how objects of legitimate scientific investigation emerge. He was interested in particular in how humans become the object of their own scientific enquiries, for instance in his study of madness and creation of medical institutions in the European context around the eighteenth century (Foucault, 1961, 1963).

In The Order of Things (1966) Foucault takes a more structural or global view of the space of the history of knowledge, wherein he identifies around sixteenth century a rupture or discontinuity in the historico-epistemological field, between what he calls the Classical Age and Modernity. According to Foucault, this discontinuity is implicated in the emergence of three fields of knowledge in the seventeenth and eighteenth centuries, which today we would call linguistics, economics and biology. The Classical Age can be called representational because a clear link was considered between words and things, such that words directly represented the objects they named. This was the point that the French title of The Order of Things - Les Mots et les Choses ('words and things') - was trying to express. However, with Modernity a gap began to appear between reality and language which meant that representation was no longer as credible and a new focus on meaning and the significance of linguistic signs developed.

Similarly, there was a transition from the classical analysis of wealth as static (Adam Smith), to an economic analysis based on the dynamic circulation of production and consumption (Ricardo and Marx). This rupture was also evident in the displacement of medical discourses in which there is a direct correlation between the pathological fact which could be perceived in the visual space of the body, with a discursive formation which centred on hidden dynamic mechanism of life now called biology - which was interpreted through the information gathered by instruments, laboratorial experiments, demographic analysis and statistical calculations (Foucault, 1969/2002a, pp. 34-43). For 
Foucault the emergence of biology as a new scientific discipline signals the entry of life into history - what Foucault later calls bio-power - and which in turn has made possible the development of what we would today call the discipline of ecology.

\section{Contextuality of Knowledge}

Foucault's work focussed on how a particular épistème dictates what constitutes genuine knowledge and truth and what does not. In a simplified manner, we can suggest that the focus of this argument is that knowledge is relative to the historical context from which it emerges, and that there is no positivist external position from which to evaluate the legitimacy of a discourse about knowledge. According to Darier (1999a, p. 12), Foucault's argument on the contextuality of knowledge has implications for discourses of the environment because, for instance the historical contextualisation of biology and in turn the environment could lead polluters to claim that if there is no objective standard by which to measure pollution and that therefore the environmental crisis is relative and so we do not need to change existing practices. However the contextuality inherent in Foucault's discursive approach does not necessarily make Foucault a relativist for whom it is impossible to know anything. On the contrary, this seemingly groundless-ground is employed to recognize that scientific knowledge retains a certain degree of uncertainty and is subject to challenge and change over time. This makes Foucault more of a contextualist or an observer of the construction of knowledge, than a relativist (Darier, 1999a, p. 10).

The criticism of Foucault's archaeology centres on the tension inherent in its structural approach in the sense that Foucault claims to reveal deep historicoepistemological structures of the conditions of knowledge while maintaining the contextuality of knowledge, including presumably his own archaeology: a criticism which likely finds Foucault's archaeology as implausible as its empiricist cousins. Foucault was also criticised by the predominately Marxist oriented argument that 
archaeology is too focused on ideal categories of knowledge and so ignores social relations and everyday life, to which Foucault responded in his next works through the development of a genealogical approach to the analysis of systems of power that regulate discursive and non-discursive practices and the docile bodies which they discipline and control.

\section{Genealogy: Bio-Power, Bio-Politics, Eco-Politics}

In the seventies, partly in response to the critique of his archaeological method, Foucault began his research into the relationship between knowledges and powers through the development of his genealogical approach, a period which includes his main books (Foucault, 1969/2002a; 1975/1977; 1976/1998) and numerous articles and interviews. ${ }^{3}$ These works are concerned with the emergence of what Foucault calls power-knowledge, a concept intended to indicate how power and knowledge have become manifestly reliant upon each other, such that the extension of one is the simultaneous extension of the other. Foucault began this period with a genealogy of the emergence of disciplinary power in Europe in the eighteenth and nineteenth centuries, a new form of power which controlled life at both an individual and population level and which was crystallised in what he calls bio-power.

Foucault (1976/1998, pp. 86-87) argues that the great monarchic and state institutions that developed in the Middle Ages, rose up above the entangled and conflicting multiplicity of prior feudal powers, by establishing a principle of right or law that transcended all the varied former claims; the law to which the sovereign then identified his will and which he employed through mechanisms of prohibition and punishment. The law was not just something skilfully used by monarchs but also the diagram of its mode of materialization, a form of power which was centred on the sovereign's right to "take life or let live" (Foucault, 1976/1998, p. 136 emphasis in the original). This form of sovereign power was not an absolute form according to Foucault, 
but a discontinuous structure of power which, if it focussed on an individual, aimed to dramatise the sovereign's might through spectacular public displays of punishment ending in death. The sovereign "right to life" was a form of deduction or seizure, a subtraction mechanism to "appropriate a portion of things, time, bodies, and ultimately life itself" (Foucault 1976/1998, p. 136).

Foucault claimed that since the classical age there has been a profound transformation of the mechanism of power in the West. The sovereign form of deductive power has

tended to no longer be the major form of power but one element among others, working to incite, reinforce, control, monitor, optimize, and organise the forces under it: a power bent on generating forces, making them grow, and ordering them, rather than one dedicated to impeding them, making them submit, or destroying them. (Foucault, 1976/1998, p. 136)

This transformation is consistent with what Foucault calls a change from a sovereign society to a disciplinary society. Foucault insists that in disciplinary societies, whilst external wars are bloodier than ever, and regimes visit holocausts upon their own populations, these wars are not to be considered as waged in the name of the sovereign, but in the name of the existence of everyone,

Entire populations are mobilized for the purpose of the wholesale slaughter in the name of life necessity ... It is as managers of life and survival, of bodies and the race, that so many regimes have been able to wage so many wars, causing so many men to be killed. (1976/1998, p. 137).

Power, Foucault argues, is now situated and exercised at the level of life.

Foucault (1976/1998, p. 93) argues that in a disciplinary society, power does not exist in a single point or emanate from a unique position of sovereignty but that it has become a rhizome of force relations (to use Deleuze and Guattari's concept), which constantly create states of power which are always local and unstable. This reveals Foucault's renewed concept of localisation, where we can see that local has two different and seemingly contradictory meanings. As Deleuze (1986/1988) describes, for Foucault "power is local because it is never global, but it is not local or localised 
because it is diffuse" (p. 26). In this sense power is everywhere not because it is homogenous, but because it passes through innumerable different points. Deleuze (1986/1988) explains here that power is neither exterior nor super-structural, but characterised by "immanence of field without transcendent unification, continuity of line without global centralisation, and contiguity of parts without distinct totalisation" (p. 27). Foucault's concept of a dynamic network of power relations in continual variation clearly shows a concern with an immanent concept of difference like Deleuze.

Foucault (1976/1998) argued that bio-power - power that operates at the level of life itself - is a form of control which he insists was an "indispensable element in the development of capitalism", the rise of which "would not have been possible without the controlled insertion of bodies into the machinery of production and the adjustment of the phenomena of population to economic processes" (p. 141). According to Rabinow and Rose (2003, pp. 2-3) Foucault delineates a bi-polar diagram of the strategies of power over life. The first pole centres on the body as a machine, an anatomo-politics operating through various techniques of discipline and control employed in institutions such as armies, schools, families, prisons and factories in order to optimize the production, availability and performance of docile bodies and their integration into systems of efficient and economic controls. The second pole centres around the organisation of power over life, power which was deployed at the level of interventions and regulatory controls of the species body, a bio-politics of the population. Bio-politics was concerned with the management of the species as the corporeal basis of biological processes and the mechanics of life, through the development of discourses of demography, and the statistical analysis and administration of migration, birth rate, mortality, public health, life-expectancy and so forth. At its most general then, the concept of bio-power serves to bring into view a field comprised of more or less rationalised attempts to intervene upon the vital 
characteristics of human existence - human beings, individually and collectively, as living creatures who are born, mature, inhabit a body that can be trained and augmented, and then sicken and die, and as collectivities or populations composed of such living beings. The analytics of population also focussed scientific attention onto discourses concerning population-resource questions, the beginning of what we today might call issues of the environment and resource management. Foucault's concept of bio-politics, when expanded to include all form of life, for instance in today's environmental discourses, can be understood as fundamental to the development of the concept of ecopolitics as the perceived control and management of the entire planet.

\section{Sex and Resistance}

The development of political technologies of life in turn identified sex, "the means of access both to the life of the body and the life of the species", as a "crucial target of a power organised around the management of life rather than the menace of death" (Foucault 1976/1998, p. 147). Foucault argued that the importance of sex as a political issue meant that far from being repressed in the Victorian discourses of the nineteenth century, sex in fact became the subject of a significant increase of various juridical and medical statements; forms of knowledge-power which functioned in addition to the law within modes of normalisation.

Foucault's research into the analytics of sexuality reveals how discursive space is not the surface projection of power mechanisms, but that it is within discourse that power and knowledge are joined. However, Foucault (1976/1998) insists that we "must not imagine a world divided between accepted discourse and excluded discourse, or between the dominant discourse and the dominated one; but as a multiplicity of discursive elements" (p. 100). Discourse is a series of discontinuous segments whose function is neither uniform nor stable. It is a complex assemblage which can be both an “instrument and an effect of power, but also a hindrance, a stumbling block, a point of 
resistance and starting point for an opposing strategy" (Foucault, 1976/1998, p. 100).

For example, the current gay, lesbian or queer identities are according to Foucault, unintended effects of legal and medical discourse creating and disciplining homosexuality in late nineteenth century Europe. These strategies of normalisation (like the creation of heterosexuality as the norm by contrasting it with the "abnormality" of homosexuality) constitute one effect of power, which in many cases is resisted by those who are categorised as abnormal (Darier, 1999a, p. 18). As Foucault states

There is no question that the appearance in nineteenth-century psychiatry, jurisprudence, and literature of a whole series of discourses on the species and the subspecies of homosexuality... made possible strong advance of social controls into this area of "perversity"; but it also made possible the formation of a "reverse" discourse: homosexuality began to speak in its own behalf, to demand that its legitimacy or "naturality" be acknowledged, often in the same vocabulary, using the same categories by which it was medically disqualified. $(1976 / 1998$, p.101)

Because relations of power are not fixed and are constantly interacting, reversals can occur which are always micro-political and local, such that power is not an abstract category but is experienced by people. Foucault's integration of legitimate and illegitimate discourse in the knowledge apparatus, is not a sense of nullifying the potential for oppositional thought, or subsuming it within a dominant space of knowledge, but in fact suggests a concept of history as a continual evolution (Bové, 1988, p. xxvi ). Discourses of power-knowledge are therefore not static forms of distribution; they are "matrices of transformations, processes of continual variation" (Foucault, 1976/1998, p. 99).

\section{Environmental Ethics}

Ecologically sustainable design can also be viewed as not only a critique of the prevalent, instrumental control of the natural world but as inserting itself precisely into the normalising strategy of an eco-politics. Ecologically sustainable design discourses cannot be seen as offering a transcendent or privileged external viewpoint, but are implicated in a multiplicitous strategy of immanent power relations, and as such can be 
both repressive and enabling. Ultimately, as Foucault (1988) astutely identifies in what seems to be his only reference to ecology, even though the ecological movement has often been in "hostile relationship with science or at least with a technology guaranteed in terms of truth", it has also legitimated its criticism in name of truth, in the "name of knowledge concerning nature, the equilibrium of processes of living things" such that ecology and eco-centrism are humanly constructed categories which are policed by alltoo-human eco-centrists (p. 15). As Darier (1999a) explains, "justifying human actions in the name of 'nature' poses the unresolved question of whose (human) voice can legitimately speak for 'nature', and the inherent dangers of such an approach" (p. 24).

Most environmental ethical theories today can be seen, in the final instance, as moralistic systems of judgement which rest upon a sharp division between nature and culture. On the basis of this division, environmental ethics in turn, claims that the essential goodness of the "natural world" should be the source of norms for human conduct. It is in the presumed "proper" functioning of the "ecosystem" that humans are urged to adopt new rules and values. Like Platonic Good, or "objective scientific truth", Nature becomes another source of principles and laws to impose upon human behaviour. In addition, as these laws are seen as universal, the norms and solutions derived from them also claim to be universal, transcending the cultural and historical.

Foucault would be sceptical of any brand of environmentalism or sustainable design which desires a world free of pollution, in which life is simpler, and social and natural harmony are established on essentialist, universal "laws of nature". For Foucault, social change, revolution or environmental activism is a never-ending activity in which tactics and "goals" are constantly re-evaluated and adapted to changing circumstances within the field of power (Darier, 1999a, p. 20). Foucault calls these forms of ethical practice the aesthetics of existence or techniques of the self:

Those intentional and voluntary actions by which men not only set themselves rules of conduct, but also seek to transform themselves, to change themselves in 
their singular being, and to make their life into an oeuvre that carries certain aesthetic values and meets certain stylistic criteria. (Foucault, 1992/1984, pp. 1011 , emphasis in the original)

Consequently Foucault argues for an anti-essentialist ethos opposed to a transcendent moralism, which requires an ethics that is immanent, historical and emergent such that ethical evaluations must be created within the changing interactions of varying relations. Foucault's "practices of freedom" are not part of a strategy to normalise or control but an ethical stance which seeks to invent new forms of life through an ecological aesthetics of existence which presents itself as the right to difference, variation and metamorphosis (Deleuze, 1986/1988, p. 106).

Following Foucault we can see that the activation of environmental issues in design discourses cannot be sought either externally to power in a transcendent position, or "behind" problems of industrial production in an essentialist Nature, but as always already folded in a multiplicitous strategy of immanent power relations which can be both repressive and enabling. Foucault's historical analyses have highlighted the important arguments for an immanent and anti-essentialist naturalism, the investigation of which I undertake in chapter 2.3., through examination of the intersection of Delueze's philosophy with the sciences of complexity. 


\subsection{Geophilosophy: Deleuze's Radical Naturalism}

In this chapter, rather than presenting a unified interpretation of Deleuze's philosophy, I will follow an interpretation as posited by Manuel DeLanda (1992, 1997, 2002a), Brian Massumi (1992), and John Protevi (2001). This reading is oriented around the intersection of Deleuze's philosophy with what are today called the 'Sciences of Complexity', a reading which also overcomes the superficial similarity between Deleuze's philosophy and the texts belonging to the 'post-modern' tradition. ${ }^{4}$ This reading is consequently centred on Deleuze's ontology, as DeLanda says (2002a p. 3), on Deleuze's world rather than on his words. ${ }^{5}$ However, this reading does considerable violence not only to the beauty and experiment style of Deleuze's writing but also because this reading is of course highly selective, as Deleuze wrote at great length on other areas of thought for example on aesthetics, with books on the literature of Kafka, Proust, the painting of Francis Bacon and also two books on cinema. However, it is the explanatory power that DeLanda's reading of Deleuze contains, which I believe makes it appropriate for the context of this chapter, as its primary concern is with Deleuze's understanding of nature and environment. Furthermore, a clear understanding of how Deleuze's world works will enable us to develop a better understanding of what a complimentary theory of design for that world would be, the task I will undertake in part 3.. However, this tactic should not be understood as a 'back to the real word' reductionism approach, as there is an explicit political-ethical dimension to Deleuze's ontology (Protevi, 2001, pp. 3-4). ${ }^{6}$ 


\subsubsection{Deleuze's Philosophy and the Sciences of Complexity}

According to DeLanda (1992, p. 129) the last 30 years has seen a Foucaultian rupture in scientific research, which is centred on the ability for matter to generate patterns that are as "information rich" as those found in organic life. Consequently, DeLanda (1992) asserts, "it seems our bodies are inhabited as much by the phenomena of 'non-organic' life as much as by the familiar phenomenon of organic life" (p.133). This implies that not only must matter no longer be seen as inert or chaotic, but capable of expressing itself in complex and creative ways. In addition it has been revealed that these same expressions occur in diverse physical, chemical, biological, neural, social and anthropological material systems and at every scale from planets to atoms (DeLanda, 1992, p. 135). These discoveries have been examined by the work of the so called sciences of complexity, and it is in regard to these discoveries that according to Bonta and Protevi (2004, p. viii) lies the urgency of Deleuze's philosophy, as it is able to make sense of this world of fragmented space, twisted time, and the nonlinear effects of far-from-equilibrium thermodynamics as posited by complexity science.

This productive interaction with contemporary science also highlights the fundamental differences between Deleuze and the textural concerns of the postphenomenology of Derridean deconstruction (with its certain Heideggerian allergy to science), and in particular to most forms of post-modernism. For Bonta and Protevi (2004, p. 7), Deleuze also helps us get out from the conceptual gridlock of linguisticality of 1980's post-modernism or most interpretations of deconstruction, with their reduction of structure to text and signification. ${ }^{7}$

This frustration with the impasses of post-modernism is echoed by Massumi (2000, unpaged), for whom the Humanities have been stuck in a Euclidian space obsessed with binaries such as inside and outside (also present in the architectural discourses with Peter Eisenman's concern with what he calls the "decentring" of the 
inside or metaphysics of architecture). For Massumi (2000, unpaged) the attraction of science and Deleuze's productive engagement with science, lies in the many models from physics, chemistry, biology, and mathematics that do not start with inside/outside, but rather with concepts such as open systems and models of continuity, which allows us to think differently and tackle problems in a new way. However there are issues involved with using scientific models in philosophical or cultural discourses, the legitimacy of which was the subject of the so called "Science wars" of the 1990s.

Massumi (2000, unpaged) posits his "poaching" of science as a translation or a transposition, rather than trying to make cultural theory scientific or a form of applied science (as he states, if it was already scientific there would be no point in having cultural theory in the first place). Massumi posits a more experimental approach which tries to invent the equivalent in a different field and "let it loose" in order to open up new potentials, and to think differently. This is exactly what he has been criticised for doing in the so called Science wars of the 1990s by the "territorial manoeuvre" of Sokal and others, scientists who "appoint themselves as the policeman of the boundaries of science" (Massumi, 2000, unpaged). Massumi argues that instead an interdisciplinary approach is needed.

For DeLanda (DeLanda, Protevi and Thanem, 2005, p. 2) the urgency of Deleuze's philosophy lies in that he has rescued realism as a philosophical position. DeLanda (2002a, p. 2) presents his work as a reconstruction of Deleuze's ontology, the domain of philosophy which is concerned with the set of entities a philosopher is committed to assert actually exist, or the types of entities which according to that philosophy populate reality. The theoretical resources that DeLanda uses in his reconstruction come from mathematics (group theory, differential geometry) as well as the hard sciences of physics, chemistry, biology (far-from-equilibrium thermodynamics, autocatalysis, embriogenesis). However this could be criticised as a vicious circle, as 
how can DeLanda claim to develop a realist ontology, one that is supposed to serve as a foundation for scientific knowledge, while presupposing objective scientific knowledge in the first place? According to DeLanda (2002b, p. 2) if the point of a realist ontology was foundational, then indeed this is a problem. However, DeLanda claims this can be avoided if one does not believe in rock solid foundations. In that case you can lift up the arguments by their "bootstraps" by assuming a little bit of objective knowledge and accounting for the rest. DeLanda gives the example of the software hardware problem in computers, where software must be loaded onto hardware, but loading is a software function; this is overcome by having a little bit of software hardwired. In addition, DeLanda argues that an ontology in which there are no general laws (as in his reconstruction) would be radically different from that of standard science, and in this version science would not therefore be dependent on science's own ontology.

This method also presents the problems of the use of models taken from science. DeLanda (2003) claims the appropriation of scientific models into this reconstruction of Deleuze's ontology is not metaphorical:

The key ideas of complexity theory (the ideas of "attractor" and of "symmetrybreaking bifurcation") come from real properties of mathematical models. They are not just linguistic "concepts." And more importantly, they have turned out to be properties of many different models, that is, they are independent of the specific mechanisms in which they are actualized. (Pt. II, para. 4)

It is this mechanism-independence according to DeLanda, which makes it promising that they will be useful elsewhere (in design for example) since this independence may be evidence of a deeper isomorphism underlying very different processes that can be established non-discursively. Deleuze's concept of the virtual or Body-without-Organs is precisely an attempt to think this underlying reality.

\section{Realism and Idealism}

Realism is often criticised as naïve, and indeed Deleuze once described his own work as "naïve", 
[Foucault] may perhaps have meant that I was the most naive philosopher of our generation. In all of us you find themes like multiplicity, difference, repetition. But I put forward almost raw concepts of these, while others work with more mediations. I've never worried about going beyond metaphysics . . . I've never renounced a kind of empiricism. . . . Maybe that's what Foucault meant: I wasn't better than the others, but more naive, producing a kind of art brut, so to speak, not the most profound but the most innocent. (1995, p. 88-89)

The most common form of realism is called nä̈ve realism, which refers to a common sense theory of perception that holds the view that the objects we experience everyday have the properties that they appear to us to have. For instance, if I have an experience of a large apple tree, that is because there is a large apple tree in front of me and that apple tree will continue to exist when I am no longer there to perceive it. If the apples on the tree appear to be red, that is because they have the property redness. As common sense as naïve realism may be, it has serious problems, one of which is the problem of the variability of perception. The same object may appear differently to different people or to the same person at different times. The apples may appear to be red in the daytime, but at dusk they are a shade of grey. Thus, for philosophers like Kant, reality may exist independently from the human mind that perceives it, but we can never know for sure what that reality is like, so their ontology is restricted to phenomena, appearances as they look to humans. For such philosophers reality has no meaningful existence independently from human minds and so their ontology consists mostly of mental entities, whether these are thought as conceptual categories, transcendental objects, as linguistic representations or social conventions. This ontological stance is usually referred to as idealism. The important implication of this position is that experience becomes intrinsically conceptual and that therefore we can never go beyond experience. Social constructivism and post-modernism are called neoKantian because there is the combination of the conceptuality of experience, combined with the argument that consciousness is structured as a language resulting in the linguisticality of experience. When the linguisticality of experience is combined with 
Saussure's arbitrariness of the signifier argument, the conclusion formed is that the conceptual categories that articulate experience are themselves arbitrary since they depend on the particular language of a particular culture, and therefore each culture literally lives in its own "world". This situation restricts the construction of problems within the context of language, thus reducing actions such as torture and other physical actions that Foucault analysed in Discipline and Punish (1975), to discursive or linguistic effects.

Second there are empiricist philosophers such as Hume who, though they grant objects of everyday experience a mind independent existence, remain sceptical that theoretical entities (both unobservable relations such as physical causes as well as unobservable entities such as electrons) possess such mind-independence. For Hume the linguisticality of experience does not exist. Physical events, sensations and perceptions have one logic, social ideas and representations have another, they are both real and importantly they interact. Pragmatists, positivists (the official position of science) and instrumentalists of different kinds all subscribe to one or another version of this ontological stance.

Then there are philosophers who grant reality full autonomy from the human mind, disregarding the difference between the observable and the unobservable as betraying a deep anthropocentrism. In other words, while the previous stances deal only with phenomena (things as they appear to the human mind) the latter also includes nuomena (things in themselves). Philosophers adopting this stance are said to have a realist ontology. Deleuze is such a realist philosopher.

\section{Realism and Essentialism}

In some realist approaches, such as naïve realism, the world is thought to be composed of fully-formed objects whose identity is guaranteed by their possession of an essence or a core set of properties that define what these objects are. Deleuze is not a 
realist about essences. Instead of categories and particular instantiations (a set of particular objects belong to a category if they share a common core of essences or properties), Deleuze argues for universals and singularities, or wholes and parts, where singular individuals can be working components of a larger (singular) spatio-temporal individual which emerges from the interactions of the population of smaller individuals, and which can have causal powers of its own. For instance, categories such as animal species are replaced with larger spatio-temporal individuals, so that a given species is as singular, unique and historically contingent as the organisms that belong to it. The relation between organisms and species is therefore not one of particular instantiations belonging to a category, but one of singular individual organisms as the working component parts of (larger) singular individual species which emerges from their interactions. This is a more radical position than either, simply ignoring categories and sticking to particular instantiations, or declaring all categories to be social constructions. Certainly, not all categories identify a larger individual in the world, for example schizophrenia may actually be a group of several different mental conditions. However, it is also wrong to claim that every category is a social construction and therefore to not claim that all categories are social constructions is essentialism. Actually the opposite is true; replacing essences with social constructions quickly degenerates into social essentialism.

According to DeLanda (2004a, unpaged) the real question is whether it is legitimate to have an anthropocentric ontology, that is, to draw the line between the real and the non-real by what we humans can directly observe. What makes our scale of observation, in space or time, so privileged? Why should we believe in the Hutt River but not in oxygen or carbon? Why should we study things in "real time" (that is, at our temporal scale) instead of at longer periods (to capture the effect of long durations)? Can we really be so time provincial? Should we not consider the nature of reality prior 
to human existence as well? A broader time scale is required which is not limited to the human time scale of observation.

Getting rid of essences and general categories is difficult, however Deleuze achieves this without falling victim to transcendent illusions or universal, eternal essences. How he overcomes this forms the originality of his philosophy of nature. First, the identity of each singular spatio-temporal individual needs to be accounted for by the details of the individuation process that historically generated the entity, which Deleuze calls processes of stratification or consolidation, and which I examine in 2.3.2.. Second, any regularity in the individuation processes themselves and especially any recurrent features in different processes must be accounted for in terms of an immanent abstract structure which Deleuze terms Abstract Machines, the nature of which I examine in 2.3.3. 


\subsubsection{Trees and Rhizomes}

As we saw in the philosophy of Foucault (chap. 2.2.), post-structuralists very infrequently refer to Naturalism, and if they do it is generally in hostile enquiry, because of naturalism being taken as the equivalent to essentialism. This definition of naturalism holds that not only is there a "dualism of absolute essence and incidental appearance, but also that what is essential is intrinsically more valuable morally and aesthetically" (Foucault, 1988b, p. 119-120). Deleuze is a significant exception because he provides a philosophical naturalism that is consistent with the critiques of essentialism and dualism.

Hayden (1998, p. 104) argues that Deleuze does not shy away from the problematic discourses concerning nature and naturalism, and rather than focussing on society or nature, as if they are mutually exclusive, on society and nature in reciprocal presupposition. This is not a reintroduction of essentialism or dualism: for Deleuze there is no unchanging, original nature "behind" society, and neither are society and nature opposed and hierarchically divided absolutes. Deleuze's philosophy of nature "highlights the immanent, historical interconnections between coextensive social and natural worlds, in such a way that he provides some philosophical resources for integrating ethical and political considerations with ecological concerns, while resisting the reductive temptation to turn nature into a static metaphysical foundation" (Hayden, 1998, p. 104).

Deleuze does not fall victim to the naturalistic fallacy because of his critique of essentialism and vitalism. For Deleuze, matter is not chaotic or inert but is capable of self-organisation, an aspect which is highlighted by the intersection of his philosophy with the sciences of complexity. Throughout the history of philosophy matter has generally been considered as inert mass and that therefore the genesis of forms involves 
an external power beyond matter itself in the form of transcendent eternal essences. This concept of the genesis of form is called hylomorphism. However, Deleuze provides a theory of the genesis for the individuals of the actual world which accounts for their identity through the analysis of their historical processes of production.

\section{The Stratification of Trees and the Consolidation of Rhizomes}

Starting the distinction in the most general way, we could say that it is between stratified systems or systems of stratification on the one hand, and consistent, selfconsistent aggregates on the other... there is a coded system of stratification whenever, horizontally, there are linear causalities between elements; and, vertically, hierarchies of order between groupings; and holding it all together in depth, a succession of framing forms, each of which informs a substance and in term serves as a substance for another form. ... On the other hand, we may speak of aggregates of consistency when instead of regulated successions of formsubstances we are presented with consolidations of very heterogeneous elements, orders that have been short-circuited or even reverse causalities, and captures between materials and forces of different nature: as if a machinic phylum, $a$ destratifying transversality, moved through elements, orders, forms and substances, and molar and molecular, freeing a matter and tapping forces. (Deleuze \& Guattari, 1980/1987, p. 335, emphasis in the original)

From the quote above, the Deleuze's philosophy could appear to have very little in common with the empirical discipline of science or the environment and would indeed seem more at home in the linguistic or literary theory of post-modernism. ${ }^{9}$ However, the intersection of Deleuze's philosophy and complexity science, in recent readings of their work by DeLanda, Massumi, Protevi and others, which although controversial, has enabled greater productive interaction between Deleuze's thought and the arguably more empirical concerns of issues of the environment. In fact, we can find in Deleuze a rigorous and pragmatic philosophy of environment.

In A Thousand Plateaus (Deleuze \& Guattari, 1987), Deleuze describes the two general types of structures most often found in the actual world, which he terms trees and rhizomes or alternatively strata and consistencies. Strata are stable, hierarchical systems of homogenous elements, whereas consistencies are precisely the manifestation of heterogeneous elements in itself. The distinction between discrete, hierarchical structures and continuous, network structures has come to occupy centre-stage in 
several different contemporary philosophies, such as in economist and artificial intelligence expert Herbert Simon's (1969/1996, pp. 32-35) distinction between bureaucracies and markets - human institutions which emerge alternatively from centralised and decentralised control; work which has been particularly influential in design research. However Simon's distinction between command hierarchies and decentralized markets may turn out to be a special case of a more general dichotomy. In fact, Deleuze claims that the distinction between hierarchies and markets, or strata and consistencies is defined not so much by the locus of control, as by the nature of the elements that are connected together. Strata are composed of homogenous elements, whereas consistencies articulate heterogeneous elements. For example, a military hierarchy allocates people into internally homogenous ranks before joining them together through a chain of command. Markets, on the other hand, allow for a set of heterogeneous needs and offers to become articulated through the price mechanism, without reducing their diversity (DeLanda, 1995, para. 1). According to Deleuze, homogenous hierarchical structures are formed in a process of stratification, which draws matter from the environment and organises it to produce stable structures.

\section{Stratification: The Double Articulation of Content and Expression}

Stratification operates by double articulation, a twofold process producing stable hierarchical structures in all aspects of the world, from the inorganic register, to the organic register, and the alloplastic register (social-technical-linguistic), as a way to appropriate matter-energy flows from the earth and build a layer that regulates the flow. ${ }^{10}$

The first articulation chooses or deducts, from unstable particle-flows, metastable molecular or quasi molecular units (substances) upon which it imposes a statistical order of connections and successions (forms). The second articulation establishes functional, compact, stable structures (forms), and constructs the molar compounds in which these structures are simultaneously actualized (substances). (Deleuze \& Guattari, 1980/1987, pp. 40-41) 
Each layered structure or stratum, displays a relation of content and expression, which in turn have their own form and substance (Table 2). Double articulation is a two step process: the first articulation is sedimentation which selects homogenous materials (substance of content) from a subordinate flow of matter-energy, which is then deposited into layers (form of content). The second articulation is folding which establishes new connections between elements (form of expression) and creates a stable functional structure with emergent properties at another scale (substance of expression). In the following text I will detail the production of strata by the process of double articulation in the inorganic, organic and alloplastic registers. ${ }^{11}$

Table 2

The Double Articulation of Content and Expression

Sedimentation Folding

\begin{tabular}{|c|c|c|}
\hline & Content & Expression \\
\hline 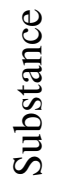 & Materials & Structures \\
\hline E్ర & Layers & Connections \\
\hline
\end{tabular}

The inorganic register, geology, sedimentary rock: Geological strata reveal an instance of the double articulation process involved in the production of hierarchical structures in the inorganic register. An exposed section of a mountainside can display the striking characteristic of stacked layers of rocky material which upon closer investigation, reveals each layer of rock to be composed of additional layers of small pebbles that are nearly the same size, shape, and chemical composition. This 
improbable distribution of homogenous pebbles deposited in uniform layers (since pebbles in nature do not come in standard sizes and shapes), suggests that some kind of sorting mechanism is involved that takes a multiplicity of pebbles with heterogeneous qualities and distributes them into uniform layers, specifically the layered organisation of sedimentary rock such as sandstone or limestone.

As a part of the greater geological cycle, the principle process for the creation of sedimentary rock involves the weathering and erosion of raw materials (stones, pebbles, grains) which are then captured by rivers, which select and separate the material by grain size and shape through processes called hydraulic sorting. Rivers act as a kind of "self-organised hydraulic computer" which, because of the variable nature of its flow along its course to the sea (sometimes calm, sometimes turbulent), affect the pebbles it

Figure 1

Sedimentary Strata Displaying Layering of Homogenous Materials at Different Scales
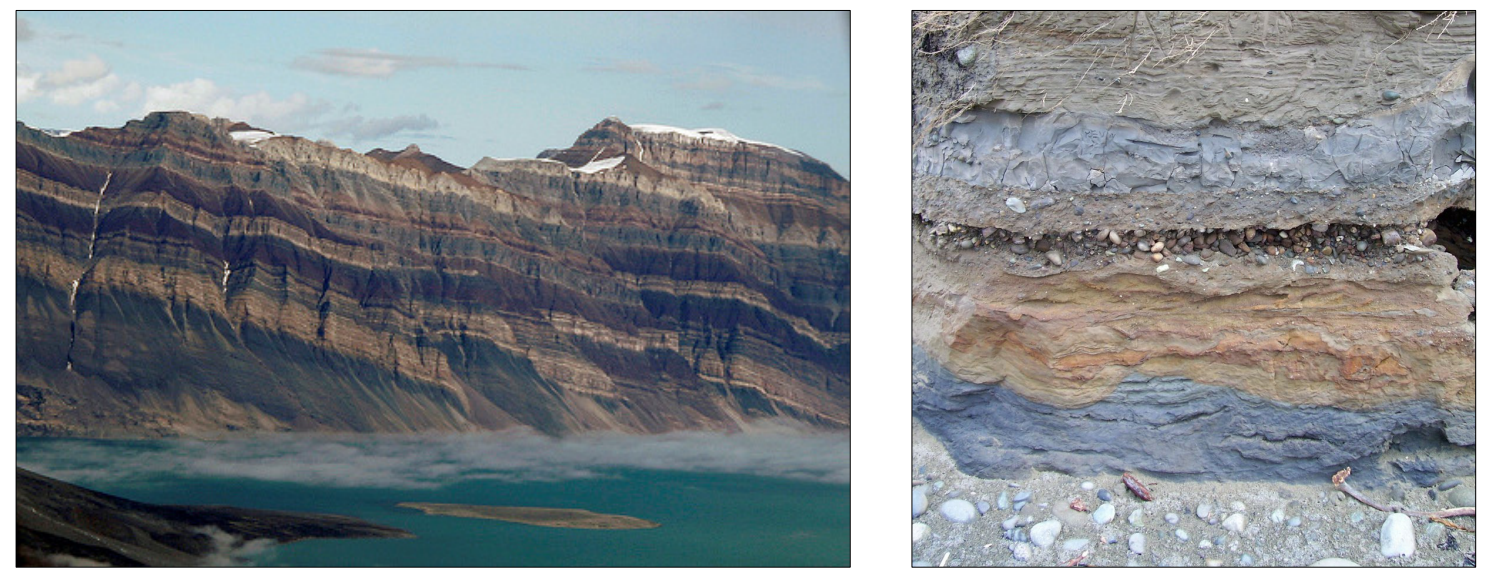

transports differently (DeLanda, 1999, p. 122, emphasis in the original). The changing dynamic of the flowing water sorts the pebbles, with the smaller pebbles reaching the ocean sooner than larger ones. Once the pebbles reach the ocean the sorted material accumulate into more or less homogenous deposits in a process called sedimentation. 
The deposits of sediment then undergo a second process whereby the loose collections of pebbles are transformed into a stable structure at a larger scale; sedimentary rock. In the case of limestone this process involves the cementing of the structure by soluble substances such as silica, (or in the case of sandstone, hematite) which penetrate the sediment through the pores between pebbles and crystallises, locking the pebbles' temporary spatial relationship into a more or less permanent architectonic structure. ${ }^{12}$

At a larger spatio-temporal scale, these rock layers are then folded under tectonic pressure of molten rock flowing up from beneath the Earth's crust to emerge as mountains - which are then sculpted by erosion, and transported to the sea, and so on ad infinitum. The historical process of double-articulation assembles the pebbles into a new structure at a larger spatio-temporal scale, with its own emergent properties. At any time we can understand portions of this cycle or flow actively undergoing process of self-organisation (flows of hydraulic computers, convection of lava driving plate tectonics) and other portions having become stratified into more or less stable or rigid structures.

Organic register, biology, speciation: We can find the morphogenetic operation of stratification in the organic register in the phenomenon of speciation, the process where by new species are formed. Although gene pools are designed to replicate themselves very precisely, random mutations and recombinations create the necessary variation for gene pools to evolve and undergo processes of stratification. Roughly speaking mutation and recombination plays the role of erosion and weathering in the geological cycle, in that they provide the raw materials for natural selection. According to Neo-Darwinism for example, species form by the gradual accumulation of genetic material, and the adaptive anatomic and behavioural traits that those genetic materials yield. These traits are not distributed randomly, but are selected by various pressures, including climate, mating preferences, and actions of predators and prey, which have 
the effect of sorting the fit from the unfit, or the stable from the unstable, and assembling the remainder into layers of the food chain. In a real sense, we can understand the accumulation of genetic material and behavioural traits as a process of sedimentation as in the case of the pebbles, even though the sorting device in this case is completely different.

These loose collections of genes and traits are very ephemeral and can be lost under some drastic change in conditions (like an ice age for instance) unless they become cemented into a stable structure, like that of the production of sedimentary rock from the loose layers of pebble deposits. This second process, according to macro evolutionary dynamics, occurs as the result of speciation, that is, when a portion of the gene pool becomes reproductively isolated from its parent group and the information contained in its gene pool becomes permanently injected into the larger phylogenetic lineage to which both groups belong (as in the case of horses and donkeys, when their offspring are sterile). Reproductive isolation operates in DeLanda's (1999, p. 123) terms, as a ratchet mechanism which prevents the loss of the accumulated genetic material of a population from being eroded away through devolution back to unicellular organisms. Through this dual process of selective accumulation and reproductive isolation, what was a loosely bonded set of anatomical and behavioural traits is now hardened into a more or less permanent structure of a particular species, with its own emergent properties. $^{13}$

Alloplastic register, social classes: We can also find the process of double articulation in what Deleuze calls the Alloplastic register, for instance in the stratification of social classes or castes. The production of social strata can occur when a given social system presents a variety of differentiated sets of roles or groups with different functions, meanings, purposes or resources, to which the population has unequal access. The distribution of these roles into ranks and subgroups involves 
specific group dynamics, such as when informal criteria for sorting the society into subgroups begin to form once a group who have acquired preferential access to key roles then attain the power to further restrict access to those roles. Even though roles tend to sediment through these sorting or ranking mechanisms, in most societies, ranks do not necessarily become an autonomous dimension of the social organisation. A second operation is observed whereby the informal sorting criteria become embedded and institutionalised through legal and theological codification into norms, and the elites must become the guardians and bearers of the newly institutionalised traditions, that is, the legitimatiors of change and innovation.

The examples of stratification above reveal the process of double articulation operating across the inorganic, organic and alloplastic registers, producing stable hierarchical structures composed of homogenous elements which emerge from the interactions of a population of individuals at a different spatio-temporal scale. The second most common type of structure that populates the world is what Deleuze terms consistencies, or rhizomes, self-consistent aggregates, war machines and also machinic assemblages. These heterogeneous structures are produced through the process of consolidation, examples of which can also be found in the inorganic, organic and alloplastic registers, which I detail in what follows.

\section{The Consolidation of Consistencies}

[Consistencies are] an entirely different schema, one favouring rhizomatic, rather than aborified... a distribution of an entire population... [where] there is no form or correct structure imposed from without or above but rather an articulation from within... What we term machinic is precisely this synthesis of heterogeneities as such. (Deleuze \& Guattari, 1980/1987, pp. 328-329)

Consistencies are systems, according to Bonta and Protevi (2004), that resemble “an intensive network or rhizome displaying 'consistency' or emergent effects by tapping into the self-ordering forces of heterogeneous material to mesh together ... a system that preserves the heterogeneity of its components even while enabling emergent 
systemic effects" (p. 54). DeLanda (1999, p. 125) suggests that the type of consistency most closely studied in science to date is the autocatalytic loop, a closed chain of chemical processes in which a series of mutually stimulating pairs of substances link up to form a structure that reproduces as a whole. In other words, within the chemical reaction, a component that accumulates due to the catalytic acceleration of one reaction, serves as the catalyst for another reaction, which in turn, generates a second product which then catalyzes the first reaction. Hence the loop becomes self sustaining, and can remain so as long as its environment continues to provide enough raw materials for the chemical reactions to proceed.

The pioneers in the study of autocatalytic loops, biologists Humberto Maturana and Fracisco Varela (1973/1980) developed a theory of autopoeisis (meaning "auto (self)-creation") to which they attribute two general characteristics. First, they are dynamic systems which endogenously (i.e. grows from within) generate their own stable states (called attractors or eigenstates); and second, they grow or evolve by drift, meaning that because the constraints of the system are internal, the growth of a network of autocatalytic loops is in effect unplanned, as the increasing complexity of the system does not take place in order for the loop as a whole to meet some external demand (such as adapting to a specific situation).

Autocatalytic loops present a particular instance of Deleuze's model for a general structure generating process for consistencies, which operates across the inorganic, organic, and alloplastic registers. According to Deleuze (1980/1987, pp. 328-329), the consolidation of consistencies involves a sequence of actions involving three aspects: articulations of superpositions - the bringing together of heterogeneous yet complimentary elements or functions (the reciprocal nodes in the autocatalytic loop); intercalated elements - catalysts or events that intensify the internal interaction; and finally the stable behavioural patterns occurring at regular temporal or spatial intervals 
that interlocked heterogeneities form (the oscillating chemical circuit for instance). Though Deleuze's model for the process of the consolidation of consistencies is less developed than his double-articulation model, the concept of a non-homogenising articulation of diverse elements is crucially important for his machinic philosophy of immanent production.

Inorganic register, geology, igneous rock: Besides the sedimentary type there exists another great class of rocks called igneous rocks (such as granite) which are the products of an entirely different morphogenetic process. Granite, unlike sandstone, forms directly out of cooling magma, a viscous fluid mixture of diverse molten materials. Each of these liquid components has a different threshold of crystallization due to its particular properties, such that it solidifies at a different critical point in temperature. Therefore as the magma cools the different elements separate and crystallize in sequence, forming a nested-set of interlocking heterogeneous crystals, where those that solidify earlier serve as containers for those which acquire a crystal form later. In this instance the intercalary elements from Deleuze's description are the events that initiate the next process of crystallisation in the sequence; these can be reactions between the cooling liquid magma and the walls of an already crystallized component, nucleation events within the liquid and even certain defects inside the crystals (called dislocations) which promote growth from within. The third aspect of the process involves autocatalytic chemical reactions within the cooling magma, which generate oscillating stable states, reactions called chemical clocks which alternate at perfectly regular intervals. This rhythmic behaviour is not imposed from without but is spontaneously generated from within and which can produce spatial patterns, forming spiral or concentric circles (e.g. orbicular granitoids) which can be observed in frozen form in some igneous rocks. 
Figure 2

Igneous rock with Orbicular Granitoids; Detail of Polished Granite showing Consistency of Heterogeneous Elements
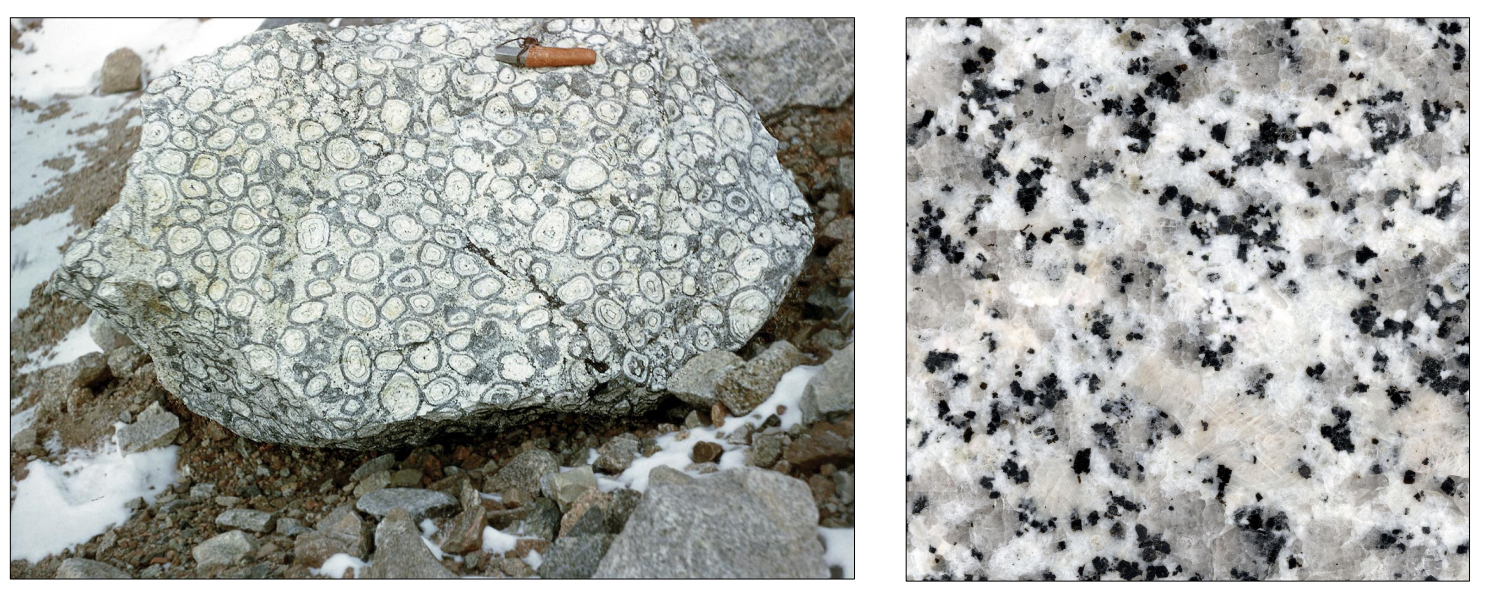

Organic register, biology, ecosystems: While speciation of a gene-pool may be considered as the prime example of an organic stratified structure, an ecosystem represents a biological realisation of a consistency. An ecosystem links together a large number of diverse reproductive communities of different animals, plants and microorganisms in a complex assemblage, through the circulation of matter-energy in the form of biomass flowing through food-webs. Biomass (stored solar energy in plant and in turn animal flesh) circulates through the functional nutritional couplings of particular prey/predator and parasite/host relationships. In this situation, intercalary elements are the symbiotic relations which help to build functional couplings between heterogeneous elements, such as the micro-organisms that line the guts of herbivores which allow them to digest cellulose, or the bacteria that allow legumes to fix nitrogen, and the fungi that permit many plant roots to get access to phosphorus. Ecosystems also display nested sets of endogenous stable states, or rhythmic, periodic patterns of change at different timescales or intervals. There are different cycles of nutrients such as the carbon and nitrogen cycles, seasonal cycles, the fluctuations of different species' population densities, particular durations of life cycles, birth and death rates, rates of sexual 
maturation, circadian rhythms, and the characteristic relaxation time a population will exhibit in order to return to equilibrium after being subjected to an environmental shock such as a harsh winter (called its resilience).

Alloplastic register, social, pre-capitalist markets: An example of a consistency from the alloplastic register is that of markets which operate in the socio-economic domain. The more or less fluid structure of markets which arise from the spontaneous interaction of many different agents is in contrast with the more rigid hierarchical structure of a centralised State institution. DeLanda (1999, p.128) claims that mainstream economics fails to capture the fluid state of market dynamics. It assumes that markets are governed by a tendency to move towards an optimal equilibrium state from the point of view of society as a whole (full employment equilibrium), through the of perfect competition among all economic agents (that is, there are no monopolies or oligopolies manipulating prices) and that these agents have access to perfect information on market conditions and can act upon that information so as to negotiate maximum benefit. But when these assumptions are relaxed, the dynamics of markets can be seen to more clearly resemble consistencies. DeLanda gives the example of common weekly markets, places where people with heterogeneous needs for goods can meet those with supplies of them. The matching of complimentary demands, interlocking needs and supplies, is performed automatically by the price mechanism which besides transmitting information about the relative monetary value of different products, also acts as an incentive. Of course, this mechanism can only work automatically if prices set themselves in the absence of any guild or other hierarchical structure, money can be said to act as the intercalary element, because with pure barter complimentary demands must be matched by "chance", where as when money (or as other primitive forms such as salt or shells) is introduced complimentary demands can be matched "at a distance" so to speak. Markets also seem to generate endogenously 
stable states or cyclic pattern, such as the so called Kondratieff cycles in which prices and interest rates rise and fall following a fifty-two year long-wave motion.

\section{Destratification and Restratification}

The two processes of morphogenesis described by Deleuze, the double articulation of strata and the consolidation of consistencies, produce the two general types of structures most often found in the world. However, neither structure occurs in a pure form, such that the two structures present two limits or poles of any possible structure. As Deleuze writes,

From this point we may oppose the consistency of assemblages to the stratification of milieus. But once again, this opposition is only relative, entirely relative. Just as milieus swing between a stratum state and a movement of destratification, assemblages swing between a territorial closure that tends to restratify them and a reterritorializing movement that on the contrary connects them with the Cosmos. (Deleuze \& Guattari, 1980/1987, p. 337)

More commonly we find complex changing mixtures, hybrids and combinations of strata and consistencies in continual morphogenesis, such that strata give rise to consistencies, and consistencies give rise to strata. Therefore it is more accurate to consider a flow of matter-energy-information encountering processes of destratification and restratification at any one time.

Strata are the result of the congealing of intensive far-from-equilibrium processes as they reach equilibrium, a steady state or stability. This stratification is a temporary fixing of an underlying flow that enables the emergence of functional structures. Just as the Himalayan Mountains, when considered from a geological timescale, represent a temporary hardening of the Earth's crust as it is continually folded by the pressures of flowing magma driving the geological cycle, our bodies and minds can also be regarded as temporary decelerations of a flux of biomass, genes, and behavioural patterns. Languages too can to seen as temporary thickenings in a flow of semantic, phonologic and syntactic norms, where standard languages would result from the capture of that 
flow by institutional interventions, which are in turn constantly being undone by emergence of pidgins and creoles. 


\subsubsection{The Body-without-Organs}

Deleuze presents a neo-materialist geophilosophy within which flows of matterenergy-information containing an immanent power of self-organisation, undergo processes of destratification and restratification which yield the structures we observe in the world. There is a sense that the flow of matter-energy-information is therefore the primary reality and the structures that form are more like coagulations, decelerations or temporary hardenings of that primary flow. The unformed flux of destratified matterenergy-information is what Deleuze calls the Virtual, Plane of Consistency or the Body without Organs (BwO),

The organism is not at all the body, the $\mathrm{BwO}$; rather it is a stratum on the $\mathrm{BwO}$, in other words, a phenomenon of accumulation, coagulation, and sedimentation that, in order to extract labour from the $\mathrm{BwO}$, imposes upon it forms, functions, bonds, dominant and hierarchized organisations, organized transcendences... the $\mathrm{BwO}$ is the glacial reality where the alluvions, sedimentation, coagulation, foldings, and recoilings that composed an organism - and also signification and a subject occur. (Deleuze \& Guattari, 1980/1987, p. 159)

Throughout A Thousand Plateaus, Deleuze goes to great length to reveal the movement of matter-energy-information in continual variation and the inorganic, organic and alloplastic structures that emerge from that flow. The processes of destratification and restratification imply that there is no "ladder" of progress towards an ever-increasing state of perfection, but that different societies at different times have achieved varying consistencies among their flows, such that a State apparatus is not essentially better than a "primitive" society. Consequently a pragmatic ethico-political disposition is implied, where we must find the right viscosity for our flows, the exact consistency that would allow humanity to self-organise more in tune with our environments. According to DeLanda, the

Recognition that our world is governed not only by nonlinear dynamics, which makes detailed prediction and control impossible, but also by nonlinear combinatrics, which implies that the number of possible mixtures of meshwork [consistencies] and hierarchies [strata], of command and market, of centralisation and decentralisation, are immense and that we simply cannot predict what 
emergent properties of these myriad combinations will be... [This calls] for a more experimental attitude toward reality and for an increased awareness of the potential for self-ordering inherent in even the humblest forms of matter-energy. (1997, p. 273, emphasis in the original)

Deleuze gives an indication of what this experimental pragmatic attitude might entail,

You don't reach the BwO, and its plane of consistency, by wildly destratifying... If you free it with too violent an action, if you blow apart the strata without taking precautions, then instead of drawing the plane you will be killed, plunged into a black hole, or even dragged toward catastrophe. Staying stratified-organized, signified, subjected - is not the worst that can happen; the worst that can happen is if you throw the strata into demented or suicidal collapse, which brings them back down on us heavier than ever. This is how it should be done. Lodge yourself on a stratum, experiment with the opportunities it offers, find an advantageous place on it, find potential movements of deterritorialization, possible lines of flight, experience them, produce flow conjunctions here and there, try out continuums of intensities segment by segment, have a small plot of new land at all times. $(1980 / 1987$, p. 161)

Deleuze's concept of the $\mathrm{BwO}$ was created in an effort to conceive the genesis of form as related exclusively to immanent capabilities of the flows of matter-energyinformation and not to any transcendent factor, whether platonic or divine. While the $\mathrm{BwO}$, as a kind of cosmic plasma of matter-energy-information or the limit of the process of destratification, appears as unformed from the perspective of an individual organism or structure, Deleuze claims that the $\mathrm{BwO}$ is in fact pregnant with a set of immanent abstract machines, blueprints or diagrams for the processes of structure generation, called phase space portraits in the terms of complexity science. However, abstract machines or diagrams are not unique to those forms; that is, they do not represent (as an essence does) that which defines the identity of those forms (DeLanda, 1997, p. 263).

\section{Diagram and Abstract Machine}

The diagram has no "intrinsic" connection with representation and is concerned with the morphogenesis of form. According to Deleuze (1980/1987) the diagram "is not physical or corporeal, any more than it is semiotic" and so must be distinguished from icons, indexes or symbols; the diagram "does not function to represent, even something 
real, but rather constructs a real that is yet to come, a new type of reality" (pp. 141-142). In DeLanda's reconstruction of Deleuze's ontology he gives examples of the operation of the diagram in the genesis of form in the sciences of geology, biology, and thermodynamics as well as in sociology and economics. Consequently we can understand the operation of the diagram as operating transversely, in that its work is concerned as much in the folding of mountain ranges, as in the making of form and sensation in the arts, or the philosophical development of ideas. ${ }^{14}$

The diagram can be described as a kind of modulator which itself does not produce forms but which emits formative or organisational influence; a process that works through difference not resemblance in an actualisation that is a differentiation, such that the concrete form produced does not resemble its diagram, and such that the same diagram can give rise to different forms. For example, in physics different populations of interacting entities may be constrained energetically in the same way, to adopt a form that minimises free energy. ${ }^{15}$

The population of molecules in a thin layer of soap film can be understood to "seek" a form that collectively minimises surface tension in the same way that the atomic components of salt crystals seek a form that minimises bonding energy. These two processes of morphogenesis can be understood as guided by the same diagram, in this case the same point of minimal energy. However, the actual forms generated, the spherical shape of a soap bubble and the cubic shape of a salt crystal, do not resemble the diagram which they actualise nor do their actual forms resemble each other. In this case there is no question of an essence of "soap-bubbleness" somehow imposing a transcendent geometric form (a sphere) from some kind of Platonic outside onto an inert collection of molecules, but the actualisation of a single immanent topological form inhabiting a diagrammatic space of possibilities. 


\section{Symmetry-Breaking Transitions}

Following DeLanda (2004b, p. 372) one way of understanding how a real yet abstract topological form can morphogenetically individuate an actual metric form, without recourse to essentialism, can be thought in geometry through the concept of a symmetry-breaking transition. Symmetry is a technical term which we can roughly define as the degree to which an object lacks detail: the blander or less detailed the object, the more symmetry it has. We can make this concept more precise through the mathematical notion of groups of transformations, a set of operations (having very specific properties) which when applied to a geometrical object change some of its properties while leaving others unchanged.

The importance of groups of transformations is that they can be used to classify geometric figures by their invariants. For example, applying the set of operations consisting of rotations by 90 degrees (that is, a set containing rotations by $0,90,180$, 270 degrees), to a cube would leave it invariant, meaning that an observer who did not witness the rotation would be unable to tell that any transformation had taken place. However, a cube would not remain invariant under a set containing rotations of 45 degrees, but a sphere would. In fact a sphere remains visually unchanged under any amount of degrees. Mathematically this is expressed by saying that the sphere has more symmetry than the cube relative to the rotation transformation. In other words the larger the group of transformations leaving the object unchanged, the more symmetry the object is said to possess (relative to that transformation).

Classifying geometrical objects by their degrees of symmetry represents a departure from the axiomatic classification of geometrical figures by their essences. While an axiomatic approach would look for a set of properties common to all cubes, or to all spheres, groups do not classify these figures on the basis of their static properties but in terms of how these figures are affected (or not affected) by active 
transformations, that is, figures are classified by their response to events that occur to them (DeLanda, 2002a, p.18). Additionally, this problematic approach allows dynamic relations to be classified in a different way. We can imagine an event in which the circle changes into the cube through losing some invariance to some transformations.

The circle is said to lose symmetry or become less bland, since the original group of transformations would be made smaller, a transition that we can now understand as a process of progressive differentiation through a symmetry-breaking transition.

Table 3

Symmetry-Breaking Transition: Invariance under Groups of Rotations

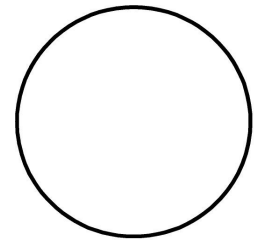

Any

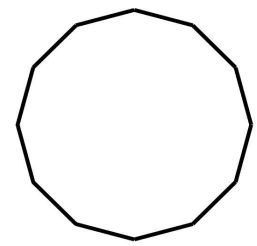

$0^{\circ}, 30^{\circ}, 60^{\circ}$, $90^{\circ}, 180^{\circ}$, $210^{\circ}, 240^{\circ}$ $270^{\circ}, 300^{\circ}$, $330^{\circ}$

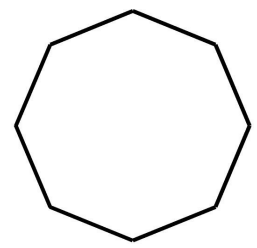

$0^{\circ}, 45^{\circ}, 90^{\circ}$ $135^{\circ}, 180^{\circ}$ $225^{\circ}, 270^{\circ}$ $315^{\circ}$

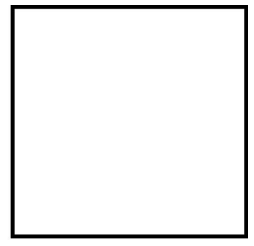

$0^{\circ}, 90^{\circ}, 180^{\circ}$, $270^{\circ}$
More symmetry

Less detail (bland)
Less symmetry

More detail

A symmetry-breaking transition presents a sequence of events in which symmetry lost through a process of progressive differentiation, a process in which an originally undifferentiated object progressively acquires more and more detail (DeLanda, 2004b, p. 372). The significance of such a process was extended by Felix Klein, one of the most important nineteenth-century mathematicians, who realised that not only geometrical figures but geometries themselves can be classified by their invariants under transformations (Table 4). As DeLanda explains,

Euclidian and Non-Euclidian metric geometries, for example, form spaces whose properties remain unaltered by a group containing rotations, translations and reflections. In other words, lengths, angles and shapes are invariant under this group of transformations. In projective spaces, on the other hand, those properties 
do not remain invariant but others do, such as linearity, collinearity and the property of being a conic section. Moreover, this group of transformations that leave the later invariant is a larger set, including rotations, translations and reflections, but also projections... and sections." (2004b, p. 373)

The group characterising Euclidian geometries (less symmetry, more detail) is a subgroup of the one characterising projective geometries (more symmetry, less detail). Accordingly, as we move down the classification from Topological to Euclidian geometry, we witness a progressive differentiation of space, with new distinct classes of geometric figures emerging one broken symmetry at a time.

Table 4

\section{Klein's Classification of Geometries}

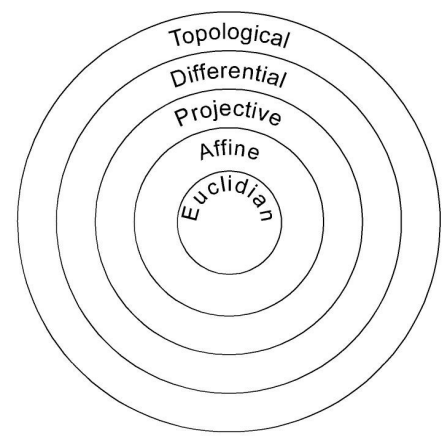

Note: Different geometries as subgroups, classified by invariants under transformations, with topological and differential geometries included.

Although the creators of these classifications saw them in a purely logical construction, in which theorems at one level are automatically valid the levels below it, according to DeLanda (2004b), Deleuze views them as morphogenetic, "as if metric spaces were literally born from non-metric ones through a loss of symmetry" (p. 373). Thus we can understand the individuation of the soap bubble and salt crystal as the differentiation of an immanent, non-metric topological form into a metric, actual object through a process of symmetry-breaking events. Furthermore, the actual form produced through this process of individuation is not defined by its resemblance or faithfulness to 
a transcendent essence, but by its dynamic response to events through the divergent actualisation of a real topological form.

\section{Possible/Real versus Actual/Virtual}

The ability of topological forms (and other abstract machines) to give rise to many different physical instantiations through a process of divergent actualisation, presents an important theory of innovation, which follows Henri Bergson as a critique the mechanical and deterministic view of causality as it was understood at the beginning of the 20th century and which is still prevalent today. As DeLanda (1998) relates, "if the future is already given in the past [as an essence], if the future is merely that modality of time where previously determined possibilities become realised [a process determined by resemblance], then true innovation is impossible", to avoid this mistake we must "model the future as open-ended, and the past and the present as pregnant not only with possibilities which become real, but with virtualities which become actual" (p. 30, emphasis in original). As DeLanda describes,

The distinction between the possible and the real assumes a set of predefined forms (or essences) which acquire physical reality as material forms that resemble them. From a morphogenetic point of view, realizing a possibility does not add anything to predefined form except reality. The distinction between the virtual and the actual on the other hand, does not involve resemblance of any kind [e.g. a topological point becomes a geometrical sphere], and far from constituting the essential identity of a given structure, the virtual form subverts this identity, since structures as different as spheres and cubes emerge from the same topological point. (1998, p.30)

The virtual $(\mathrm{BwO})$ can be understood as a continuous multiplicity that is related to the actual by a temporal process of individuation that does not operate by resemblance and is instead an open-ended evolution of genuine creativity. The $\mathrm{BwO}$ can therefore be understood as the capacity or potential for change and creativity in a system, and as such the $\mathrm{BwO}$ must not be understood as a kind of transcendent heaven or essence but as real and immanent with the actual world. The virtual is the space of emergence for the new. 
Deleuze provides philosophically for the world in a manner that emphasises the immanent capabilities of matter-energy-information to organise itself through an immanent power, that is, without recourse to any form of transcendent intervention. Accordingly Deleuze's eco-politics must also correspond to an immanent, and antiessentialist ethics.

\section{Ethology: Deleuze's Naturalism}

One of the most profound constants of Naturalism is to denounce everything that is sadness, everything that is the cause of sadness, and everything that needs sadness to exercise its power. From Lucretius to Nietzsche, the same end is pursued and attained. Naturalism makes of thought and sensibility an affirmation. It directs its attack against the prestige of the negative; it deprives the negative of all its power; it refuses to the spirit of the negative the right to speak in the name of philosophy... The multiple as multiple is the object of affirmation, just as the diverse and diverse is the object of joy. (Deleuze, 1969/2004b, p. 315)

As we have seen, Deleuze presents a notion of the world as matter in continuous variation, the limit form of which he calls the Body-without-Organs [BwO]. This continuous flux is constantly coagulating, folding, and changing at different rates through processes of destratification and restratification which create the different types of structures that populate the $\mathrm{BwO}$ : here more extensive, homogenous and hierarchical; there more intensive, heterogeneous and dynamic. The processes that create a structure or body are mechanism independent such that the body they produce "can be anything; it can be an animal, a body of sounds, a mind or an idea; it can be a linguistic corpus, a social body, a collectivity" (Deleuze, 1992, p. 629). Even though the structures or bodies that install themselves on the $\mathrm{BwO}$ cannot be detached from the flow of matter in continual variation that they are always already a part of, Deleuze claims they can be distinguished by their rates of change and their capacities to affect other bodies and be affected by other bodies, the study of which Deleuze calls ethology.

Deleuze (1992) develops this dual definition of a body in relation to Baruch Spinoza's concept of "one Nature for all bodies, one Nature for all individuals, a nature that is in itself an individual varying in an infinite number of ways... a common plane 
of immanence on which all bodies, all minds and all individuals are situated" (p. 625).

This one Nature is common to all things because it is there that life, each living individuality, is composed, not by a transcendent form or essence but by its relations of movement or rest and its capacities to affect and be affected (Deleuze, 1992, p. 626). Nature is thus seen by Deleuze (1992) as an immanent plane of life which all things enter into, both in their own individual compositions, and the complex interconnected relations they form between other compositions, such that "it is by speed and slowness that one slips in among things, that one connects with something else" (p. 626). Each thing, on the immanent plane of Nature, is defined by the arrangements of movement it enters into and the connections of the dynamic capacities each thing has to act and to be acted upon as they intersect with the capacities of others, forming a continuity "which applies equally to the inanimate and the animate, the artificial and the natural" (Deleuze \& Guattari, 1980/1987, p. 254). This does not mean that there is an undivided totality transcending particular things or that every thing is connected to every other thing, as Deleuze states the "infinity of more or less connected relations... has nothing to do with a ground buried deep within things, nor with an end or a project in the mind of God", and that nature "expresses in a single meaning all that differs" (Deleuze \& Guattari, 1980/1987, p. 254). Thus, according to Hayden (1998), while nature provides the basis for the continuity of all things, it is also the basis "for recognising the multiplicity of nature since it makes possible a rich differentiation of things in terms of the kinds of variations, interactions, requirements, circumstances, and capacities applicable to each thing and its local habitat" (p. 188). Deleuze's form of naturalism can therefore be seen as endorsing biodiversity as he argues for both the continuity of all things and the affirmation of the entire variety of nature's diversity. A form of biodiversity that is "composed of all species of micro-organisms, plants, animals, the milieux or 
ecosystems they are a part of, and the specific assemblages formed by the relationships and processes flowing between these elements" (Hayden, 1998, p. 118).

Deleuze's affirmation of Spinoza's concept of a single, immanent plane of nature, which is constructed without any transcendent factors, is carried forward into its ethical and political implications. As bodies are defined by their speeds and their affects, rather than by the possession of an essence, one does not know ahead of time what problems a body is able to solve. As Deleuze (1992) states, "you do not know beforehand what good or bad you are capable of; you do not know beforehand what a body or mind can do, in a given encounter, a given arrangement, a given combination" (p. 627). This requires an ethical approach that does not resort to transcendent values or moral laws but which involves "a long affair with experimentation, requiring a lasting prudence" (Deleuze, 1992, p. 627). As Deleuze (1992) explains, "Spinoza's ethics has nothing to do with morality; he conceives it as an ethology" (p. 627). Ethology refers to both the study of animal behaviour, and to the study of the formation and evolution of human ethos, a concept which Deleuze uses, according to Hayden (1998), “in order to emphasise the nondualistic continuity of human and nonhuman life forms and their complex environmental interrelationships, as well as to propose an overlap between the physical, biological, and chemical, and the social, ethical and political" (p. 117). Deleuze writes,

Ethology is first of all the study of the relations of speed and slowness, of the capacities for affecting and being affected that characterise each thing. For each thing these relations and capacities have an amplitude, thresholds (maximum and minimum) and variations or transformations that are peculiar to them. And they select, in the world or in Nature, that which corresponds to the thing; that is, they select what affects or is affected by the thing, what moves or is moved by it. For example, given an animal, what is this animal unaffected by in the infinite world? What does it react to positively or negatively? What are its nutrients and its poisons? What does it 'take' into its world? Every point has its counterpoints: the plant and the rain, the spider and the fly. So an animal, a thing, is never separable from its relations with the world. The interior is only a selected exterior, and the exterior, a projected interior. The speed and slowness of metabolisms, perceptions, actions and reactions link to together to constitute a particular individual in the world. (1992, p. 627-8) 
Ethology maps how organisms and environments are mutually unfolded and enfolded structures, it presents a form of cartography which Deleuze (1992) likens to music composition, such that it "defines the melodic lines or contrapuntal relations that constitute a thing” (p. 629; also Deleuze \& Guattari, 1980/1987, chap. 11). The "symphony of Nature" is a "plane of musical composition", a rhythm or refrain that constitutes the relations between components but which is not contained exclusively in any one of them. The refrain is the fold between the contraction of the octopus's muscular pocket and the water it expels as it swims, or the fold between the wasp and the orchid. As Bogue (2003) relates, "the stagemaker sings its territorial song, yet its musical motif is part of a refrain that includes its perching stick, the leaves it turns, the mate it attracts, the songs of its competitors, and the space it controls" (p. 74). Ethology "studies the compositions of the relations or the capacities between different things", and seeks not only to understand what relations affirm a given thing but also what new relations can be formed in order to compose assemblages and symbiotic couplings which are favourable to all individuals belonging to them: "How can a being take another being into its world, while preserving or respecting the other's own relations and world?" (Deleuze, 1992, p. 628). The concerns of the ethologist move from assessing existing ecological conditions to the proposal of new ways of thinking, feeling and acting, that are beneficial to the flourishing of all life on earth (Hayden, 1998, p. 119).

\section{Moralism versus Ethicism}

Deleuze's naturalism is ideally suited to issues of the environment in my opinion because it is an ecological ethics that refuses to defer to the existence of transcendent values. As we have seen in Foucault and as Deleuze frequently reiterates, to find transcendent values such as the Good or the True in a static nature is to mistake nature as an ultimate moral determinant. Ethics on the other hand, is the compliment to what 
Deleuze calls immanent modes of existence (Hayden, 1998, p. 120). This distinction between moralism and ethicism reaffirms how Deleuze's naturalism is anti-essentialist, and can reveal the trajectory for an active ecological ethics or ethos.

Deleuze (1981/1988) is critical of moral theories, such as those articulated by Plato or Kant, because morality "always refers to transcendent values" and functions as a "system of judgement" (p. 23). Moralism typically starts from a dualism between mind and nature, claiming that it is rational thought that gives access to transcendent values or principals that make moral conduct possible, while seeking to justify moral values within a framework of universal, absolute transcendent criteria that are then imposed from without upon the real conditions of existence. The universality of moral systems of judgement thus includes what is "proper" or rational within a sphere of judgement, while excluding or ignoring that which is different. In other words, the Good, the True or the Just, reside outside time and change, and are only accessible under the special condition of rational thought which is itself an attribute only of certain citizens, therefore moral theories operate by thresholds of exclusion or as a kind of boundary patrol that assigns value from a privileged transcendent position of judgement (Mackenzie, 2005b, p. 107).

Conversely, Deleuze (Deleuze \& Guattari, 1991/1994), argues that "thinking takes place in the relationship of territory and the earth" (p. 85) and that ethics does not transcend reality but is instead given within concrete situations and moments,

There is not the slightest reason for thinking that modes of existence need transcendent values by which they could be compared, selected and judged relative to one another. On the contrary, there are only immanent criteria. A possibility of life is evaluated through itself in the movements it lays out and the intensities it creates on a plane of immanence. (1991/1994, p. 74)

While morality measures types of existence against external, fixed standards, ethics is a kind of knowledge which cultivates a fluid understanding of changing affects, capabilities, needs or powers that is ongoing and never ending, because evaluation is 
itself a way of being, in Foucaultian terms a style of life or an aesthetics of existence of the one who actively evaluates. For Deleuze (1995) the difference between morality and ethics is that "morality presents us with a set of constraining rules of a special sort, ones that judge actions and intentions in relation to transcendent values," while "ethics is a set of operational rules that assess what we do, what we say, in relation to the ways of existing involved" (p. 100). Evaluation therefore changes in the same manner as characteristic of the constant variation of natural reality.

However, Deleuze's ethos is confronted with the accusation of relativism in the same manner as Foucault. According to Hayden (1998, p. 121) Deleuze's pluralistic naturalism implies the relativism of existing values but only because it affirms the contextuality of their historical emergence and genesis. While a principle of ethical relativism would hold that there are no criteria by which to determine that any one value is preferable to any other, Deleuze insists that there are criteria, but that they are immanent, historical and emergent rather then transcendent, essential and static (Hayden, 1998, p. 121). Ethics can be seen as the practice of developing an ethos which considers ethical evaluations as emerging from constantly varying relations and interactions between diverse members of a complex movement of matter-energyinformation in continual variation. An ecological ethos which Deleuze argues involves "a long affair with experimentation, requiring a lasting prudence" (Deleuze, 1992, p. 627), and a willingness to find or create what is most advantageous for even the humblest forms of matter. 


\subsubsection{Deleuze's Schizoanalytical Method}

Deleuze's study of the production of bodies and assemblages can be "referred to by various names: rhizomatics, stratoanalysis, schizoanalysis, nomadology, micropolitics, pragmatics, the science of multiplicities" (Deleuze \& Guattari, 1980/1987, p. 43). In regard to the purpose of this research, such a study can be seen as the extension of the notion of self-organising material systems - systems that refuse to submit their production to transcendent agents or eternal essences - to the eco-political and social-technical realms of design research. This position implies that design discourses are emergent structures produced when an intensive flow reaches certain thresholds that activate self-ordering patterns inherent in the material interactions of the components (Bonta \& Protevi, 2004, p. 36).

In order to claim "ontological emergence", that is, to claim the emergence of patterns in design research as real aspects of the world (consistent with the realist commitment to capturing features of the world rather than modelling phenomena), we must show the existence of attractors of the same type in many different actualisations (the same abstract machines informing structures in different systems), through the demonstration of the formation of singularities in the agent-based computer modelling of systems. Modelling complex systems involves constructing a visual representation of the behaviour of the dynamic systems, called a "state space portrait". ${ }^{16}$ If the state space portrait establishes the presence of the three basic constituents of the state space of selforganising systems: attractors, bifurcators and symmetry-breaking events, then we can claim the evidence of ontological emergence. While such modelling techniques have had success in the sciences, we are still far away from being able to model sociotechnical systems such as those studied in design research.

Therefore we have to be satisfied with the intuition that socio-technical systems are complex systems with emergent structures, without being able to model them. 
However, according to Bonta and Protevi (2004, p. 33), this does not mean that we cannot use Deleuze's intersection with complexity theory as a "folk ontology", and look for patterns and thresholds in social-technical systems. Rather, we can adopt Deleuze's call for an experimental attitude and try to open up new potentials and opportunities to think differently. A task I undertake in the next part through the schizoanalysis of the emergence of continuous models of complexity in architecture and design in the 1990's, and the consideration of the implications of the philosophy of Gilles Deleuze for design research. 


\section{Part 3. ARGUMENT: DELEUZE AND ECOLOGICAL THEORIES OF DESIGN}

This part addresses the themes of immanence and anti-essentialism encountered in the literature review, through the analysis of the emergence of continuous models of complexity in architecture and design in the 1990's. The immanent field of design research presented is interpreted through the comparison of problematic and axiomatic epistemology.

The notion of the environment as a complex system of interacting flows of matter, information, relationships and processes as posited by Gilles Deleuze can be mapped in the territory of design research through the analysis of Ezio Manzini's ecology of the artificial and Greg Lynn's concept of folded architecture. These two discourses can be considered as emerging through the transition from a discrete to a continuous diagram of complexity. In folded architecture, this transition has been characterised by the shift from deconstructivist techniques of collage and contradiction developed in the 1980's to a folded logic of continuity and curvature in the 1990's. A contiguous transition can be discerned in design discourses within the change from the external moral code of green design to the immanent ethos of ecologically sustainable design.

Following Deleuze's schizoanalytical method, the emergence and isomorphism of these two discourses can be argued to be informed by the divergent actualisation of an abstract machine. In order to examine this argument, I first analyse the continuity between folding in architecture and ecologically sustainable design by comparing and connecting their main concepts in order to establish their isomorphism (chap. 3.1.). Then through the examination of the distinction between the static complexity of 
discrete multiplicities and dynamic complexity continuous multiplicities, I determine the inherently temporal focus of these discourses.

In chapter 3.2. I investigate how this concern with the temporal nature of continuous complexity has prompted the respective development of design techniques such as diagramming in folded architecture and scenario building in ecologically sustainable design, techniques employed to negotiate the complexity of the contemporary environment through engaging time, change, and flexibility. The subsequent continuity of scenario building and diagramming, when seen as informed by Deleuze critique, I argue enables exchange and dialogue between the two disciplines, without unifying the two discourses within a transcendent totality. The implications of these analyses for design and issues of the environment are subsequently drawn out in chapter 3.3. in relation to trajectories of immanence and transcendence in design processes, as developed in Deleuze's distinction between the axiomatic method of Royal science and the problematic method of Minor science. 


\subsection{The Discrete and the Continuous in Architecture and Design}

Table 5

\section{Transitions toward a Continuous Diagram of Complexity in Architecture and Design}

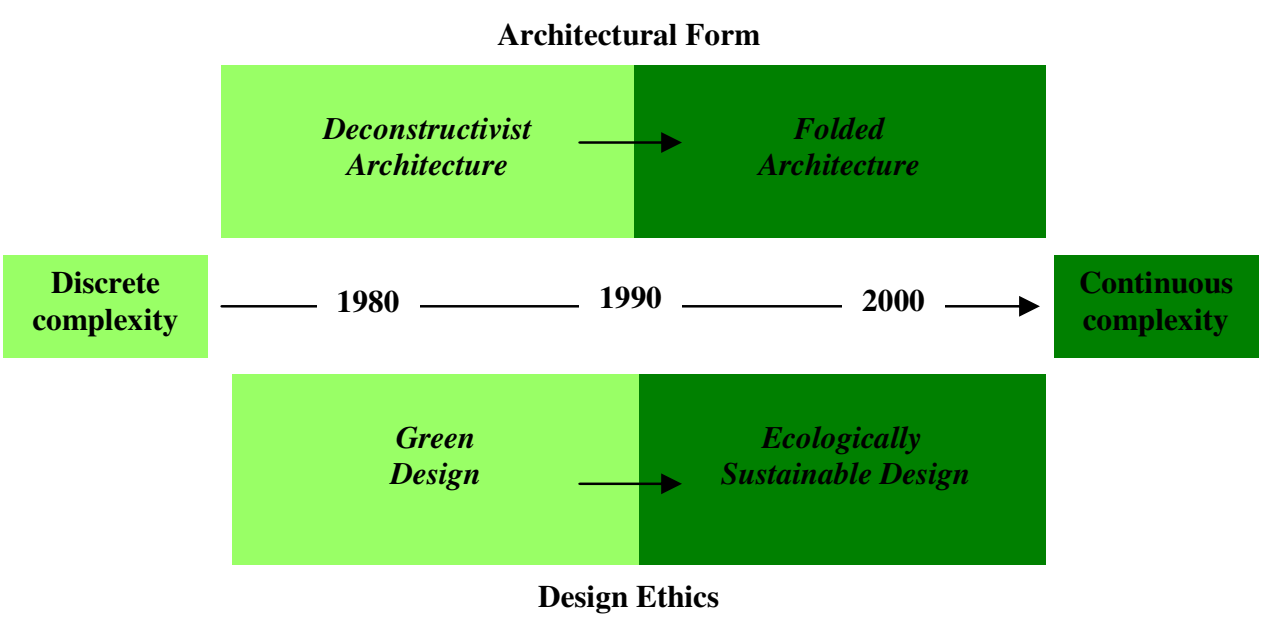

\section{Folding in Architecture}

In the key architectural text of this period, the 1993 issue of Architectural design edited by Greg Lynn entitled Folding in architecture, a number of theorists and architects articulated a concept of architectural complexity in the form of a logic of curvalinearity. This logic sought to displace the fragmentary collage of opposition and contradiction characteristic of the fragmentary forms of deconstructivist architecture, through the integration of difference in the calculus of continuous variation inherent in curved and flexible forms; the production of which was becoming increasingly accessible in conjunction with developments in computer modelling technology. According to Lynn (1993/2004), the development of this logic of curvalinearity which integrates "differences within a continuous yet heterogeneous system", is developed in relation to Deleuze's concept of the fold, which provides "a theory of synthesis and 
unity that maintains detail as a discrete moment that participates intensively in the construction of a new kind of whole" (p. 11, 24).

Folding implies a smooth relationship between diverse elements that unlike a simple hierarchy or modularity, weaves together a multiplicity of macro and micro scales whose consistency is neither exterior nor super-structural but which is characterised by "immanence of field without transcendent unification, continuity of line without global centralisation and contiguity of parts without distinct totalization" (Deleuze, 1986/1988, p. 27). According to architectural theorist John Rajchman (1993/2004, p. 78) in his essay Out of the Fold from Folding in architecture, Deleuze's concept of the fold offers an original concept of complexity that does not consist in the one that is said in many ways, but rather in the fact each thing may always diverge into many others, as in the ever forking paths in Borges' fabled garden; a kind of complexity whose fabric can never be completely unfolded or definitely explicated, since to unfold or explicate it is only to fold or complicate it anew. Thus the fold is a model of complexity that does not consist of fragments or ruins of a lost or absent whole, but in the potential for divergence with any given unity. In this manner according to Rajchman,

the concept of complexity is freed from the logic of contradiction or opposition and connected instead to a logic of intervals: it becomes a matter of a 'free' differentiation (not subordinated to fixed analogies or categorical identities) and a 'complex' repetition (not restricted to the imitation of a pre-given model, origin or end). (1993/2004, p. 78)

Following Lynn and Rajchman, the flexible complexity generated by the employment of Deleuze concept of the fold, presents a notion of complexity through divergence, which in turn reveals a transition from the notion of complexity through contradiction characteristic of Deconstructivist architecture. This transition can be interpreted as a process of destratification, as the discrete complexity of Deconstructivist architecture can be reduced to a collection of parts or aggregate of 
points, which can be seen as intrinsically divisible. On the other hand, the continuous variation of folded architecture presents a concept of complexity that is irreducible, because it is always creatively changing.

Folded architecture has also been interpreted as organic or "biomorphic" and characterised as "ecological” (Hays, Ingraham \& Kennedy, 1995, p. 9). This transition to an ecological concept of complexity has also been articulated in design by a number of authors through the concept of the ecology of the artificial (e.g. Buchanan 2000, 2001; Krippendorf, 1989/1995; Manzini 1992/1995).

\section{From Green Design to Ecologically Sustainable Design}

Since the 1960's and 1970's, ethical concerns in design have become increasingly centred on the impact of products as part of the physical and social environment rather than focussed on the personal morality of the designer or on social conditions of production (Whitely, 1999, pp. 196-200). Borrowed from the environmental movement in politics, the term green quickly became the buzz word in design culture through the 1980's with a proliferation of "how to be green" design exhibitions and design literature. As suggested by Pauline Madge (1997) green design varied from dark green to pale green, "between those who advocated a radical rejection of the status quo, a critique of the paradigm of modern industrial society (whether capitalist or socialist), and the lighter green idea of modifying existing institutions and practices" (p. 46).

The broadening of the concerns of designers from simply adding environmental criteria into existing design processes to critically reconsidering design and industrial practice, follows a transition in the 1980's and the early 1990's from pale green design to the darker green of ecologically sustainable design. For example, as proposed by Anne-Marie Willis at the international EcoDesign Conference held at RMIT in 1991, "ecodesign has the potential to be more than the reform of existing design, for if taken 
seriously; it can establish a new foundation for design that could bring economic and ecological need into a new union" (Quoted in Madge, 1997, p. 50).

This transition towards an ethics immanent with design rather than in the form of a transcendent moral code, is also supported by Alain Findeli in his 1994 paper Ethics, Aesthetics and Design. Findeli (1994), argues that the cartographic mapping of the world of artefacts in a topological plane "represents the world of artefacts as a continuous space, [which suggests] the possibility of describing it by the means of a unified theory" (p. 52). For Findeli (1994) this notion of a continuous topological model enables us "to envision continuity between the technological act and the moral act," such that it is "not necessary to leave the field of design in order to construct a general problematic of design ethics" (p. 66, 67). Findeli's argument is representative of the transition from green design with its emphasis on the political morality of the designer and a professional code of ethics that is external to the design process, to an immanent ethos in which ethics and aesthetics can be seen as continuous. In addition, this transition greatly broadens the scope of design from simply solving problems to, following Ezio Manzini, the concept of the designer as a conceiver of scenarios. The influence of Manzini's work has also played a significant role in the transition towards a more continuous diagram of complexity in design.

In Manzini’s important essay on ecologically sustainable design, first published in 1992, one year before Lynn's Folding in architecture, entitled Prometheus of the Everyday: the Ecology of the Artificial and the Designer's Responsibility, Manzini develops an ecological image of the contemporary artificial environment as a dynamic system of interacting flows of material and immaterial artefacts, which relate and compete with each other within a limited space. According to Manzini (1992/1995, p. 220), this recognition of products as elements in a complex network of relations carries an ethical imperative for the designer to choose to participate in the development of a 
new strategy of consumer production more favourable to the environment, and therefore to a new "sensuous horizon" for design based upon new values and new concepts of quality.

Manzini argues that the reductive, western enlightenment image of thought where progress is based on the continual and cumulative domination of nature by reason has lost its force today. This "culture of doing" is characterised by Manzini as really an idea about the democracy of consumption linking together the notion of well-being with increasing quantitive growth. The result of which has been the diffusion of worthless, disposable products lacking in cultural or spiritual significance; products which leave no trace in our memories but do leave an increasing mountain of rubbish (Manzini, 1992/1995, p. 222, 225).

Manzini (1992/1995) maintains that we lack a modern day value system of "everyday things", and what we need is a new approach to design which he portrays as an ethics of "minute choices", where "caring for objects can be a way of caring for that larger object that is our planet" (p. 239). Like Findeli, Manzini argues that we need concepts that map designs in terms of quality rather than quantity, which in turn enables us to understand reality without losing what we have discovered about its irreducible complexity. According to Manzini (1992/1995, p. 236), this sense of contemporary artificiality requires an ethics and aesthetics that is not based on universal and absolute ideals but refers to a system of values exhibiting the consciousness of relativity, and that attributes worth to materials and products that in some way are able to embody vestiges of their earlier existences. What Manzini is advocating here is an immanent ethics of dynamic relations between individuals consistent with the concept of a continuous diagram of complexity. 


\section{The Isomorphism of the Fold in Architecture and Ecology in Sustainable Design}

The shift in architectural discourse from deconstructivist techniques of collage and juxtaposition to the smooth curvalinearity of folded architecture follows a transition from a discrete complexity that maintains difference in contradiction, to a continuous complexity where difference is "freed" in the intensive folding of continual variation. This pattern also emerges in the transition from green design to ecologically sustainable design through the shift in design ethics from a transcendental moral code to an immanent design ethos of dynamic relations between individuals. We can therefore see the isomorphism between Findeli and Manzini's ethos of ecological mapping in design and Lynn's folded logic of curvalinearity in architecture. This isomorphism, can be considered as consistent with the Deleuzian argument and that the emergence of these two discourses are informed by the actualisation of the same abstract machine or diagram, operating across the disparate fields of architectural form and design ethics. In light of these arguments, I argue we can make non-discursive comparisons and develop a dialogue of exchange between the disciplines of architecture and design, without theorising architecture "as design" or vice versa. This suggests an immanent field of design, rather than unity of the two discourses within a transcendent totality.

Accordingly, design ethics can now be considered through processes of continual folding, unfolding and refolding, such that ethics becomes more of a Foucaultian art of existence or a style of freedom, where one continually creates and recreates oneself in order to give life the most beautiful possible form, both in the eyes of others, of oneself, and for future generations (Foucault, 1988a, p. 259). This continuity between ethics and aesthetics is maintained by Manzini in his call for a new qualitative sensuous horizon of design, because it is through aesthetics that ethics and everyday life are folded. This call for a new ethico-aesthetic paradigm in design is reiterated by Deleuze:

For there is no other aesthetic problem than that of the insertion of art into everyday life. The more our daily life appears standardised, stereotyped and 
subject to an accelerated reproduction of objects of consumption, the more art must be injected into it. (1968/2004a, p. 365)

Aesthetics now develops a pragmatic attitude, it becomes functional in that its problematic is to reconnect us with the world through the creation of events which in turn open us up to the non-human universe of which we form an ineluctable part.

The concepts of complexity investigated here, the folded logic of curvalinearity and the ecological mapping of design, are concepts of a dynamic form of consistency between heterogeneous elements, and hence both are inherently temporal concepts. The relation between folding in architecture and ecologically sustainable design can be further explicated through the investigation of the isomorphism between the design techniques of scenario building in design and diagramming in folded architecture, techniques which were developed to negotiate the complexity of the contemporary environment through engaging time, change, and flexibility (chapter 3.2.). However, in order to concretely appreciate the dynamic form of complexity which scenario building and diagramming address, we can first examine Deleuze's distinction between the static nature of discrete multiplicities and the inherently temporal nature of continuous multiplicities.

\section{Discrete Multiplicities and Continuous Multiplicities}

Deleuze considers two models of complexity with what he calls discrete multiplicities and continuous multiplicities, (also corresponding with the distinction between strata and consistencies as examined in chap. 2.3.). These concepts are based on Henry Bergson's reworking of the distinction originally made by the mathematician G. B. Riemann between discrete manifolds and continuous manifolds. This distinction defines discrete multiplicities as extensive magnitudes whose nature remains the same after they are divided, and defines continuous multiplicities as intensive magnitudes whose nature is changed each time they are divided. According to Deleuze's interpretation 
[A discrete multiplicity] is represented by space... It is a multiplicity of exteriority, of simultaneity, of juxtaposition, of order, of quantitative differentiation, of difference in degree; it is a numerical multiplicity, discontinuous and actual. The other type of multiplicity appears in pure duration: it is an internal multiplicity of succession, of fusion, of organization, of heterogeneity, of qualitative discrimination, or of difference in kind; it is a virtual and continuous multiplicity that cannot be reduced to numbers. (1966/1991, p. 38)

The articulation of the distinction between discrete and continuous multiplicities is of significance to Deleuze's philosophy of immanence, because the failure to differentiate between the two multiplicities can become the source of transcendent illusions. The division between the discrete and the continuous also determines the division of complexity into two tendencies, for example the distinction between extensive and intensive properties, and between time and duration. By briefly examining these concepts, we can gain a greater understanding of the inherently dynamic and temporal form of complexity inherent in a continuous multiplicity, with which we can better critique the isomorphism of folding in architecture and ecologically sustainable design.

\section{Extensive and Intensive Physical Properties}

Following DeLanda (2002a, p. 26-27), we can understand extensive properties as quantitative magnitudes such as length, area, and volume, which can be defined as intrinsically divisible. For instance, if we divide a volume of water into two equal halves we end up with two volumes, each volume half the extent of the original volume. Intensive properties, on the other hand, are properties such as temperature, speed or pressure which cannot be divided in the same way. For example, if we take a volume of water at 90 degrees of temperature and separate it into two equal parts, we do not end up with two volumes at 45 degrees each, but with two volumes at the original temperature. However, the temperature of a volume of liquid water can indeed be "divided" by heating the container from underneath and creating an intensive temperature difference between the top and bottom portions of the liquid. The flow of heat alters the density 
and the viscosity of the fluid, such that their interactions move the system away from equilibrium and change it qualitatively. If the temperature difference is made intense enough the system crosses a critical threshold and undergoes a sequence of physical changes in kind, the defining expression of a continuous multiplicity. In the terminology of complexity science, the system undergoes a cascade of symmetry-breaking bifurcations that changes the hydrodynamic flow pattern of the fluid from the bland steady-state of thermal conduction, to the cyclic form of thermal convection, to the "chaotic" pattern of turbulence and finally a phase transition from liquid to steam.

A difference in extension is a static difference because it is a difference in quantity, which occurs within the thresholds of a particular phase state. A difference in intensity on the other hand, is dynamic and temporal because it involves a sequence of events that produce a change in quality or change in state (a symmetry-breaking transition as discussed in chap. 2.3.). The distinction between the static nature of discrete multiplicities and dynamic nature of continuous multiplicities can also be mapped in the distinction between space and time, as discussed in Deleuze's explanation of the notion of time as duration.

\section{Time and Duration}

According to Deleuze (1966/1991, p. 37), Bergson argues in Time and Free Will (1889) and Creative Evolution (1907), that when we conceive of time as a discrete multiplicity we are trapped in a spatial concept of time. Bergson argues that instead we must consider time as a continuous multiplicity or as duration, that is, as a transition that endures a change that is substance in itself. This distinction between the familiar form of "clock time" which can be divided into a series of points (seconds, minutes, hours etc.) and the continuous form of duration that is irreducible and intensive, can be examined for example in the analysis of movement in the well known paradox of Zeno's arrow. According to Boundas, 
It was Zeno who showed that an arrow will not fly if it has to pass first, one by one, all the discrete points at the discrete times of an extended manifold; it will not fly because movement cannot be reconstituted on the basis of instants any more than being can be reconstituted on the basis of presents... instants, being durationless snapshots of movement, cannot be the building blocks of movement, because the latter presupposes mobile segments of duration... [it is] because a continuum cannot be reduced to a discrete manifold (to an aggregate of points) that movement cannot be reduced to that which is static. (1996, p.83)

If a sequence of events in a process has no effect on time, then time becomes merely a container for the events happening in it. Such a concept would become the denial of time as a change that is substance in itself, and would instead conceive time as merely a parameter unaffected by the transformation it describes. Rather, in Deleuze's words (1968/2004a), “Time itself unfolds... instead of things unfolding within it” (p. 111). According to DeLanda (2002a, p. 102), Deleuze's interpretation of duration is a concept of virtual time, in which the emergence of extensive properties of temporality should be treated as an intensive process by which a virtual continuous multiplicity (duration) progressively differentiates into actual discontinuous spatio-temporal structures (clock time).

The difference between discrete multiplicities and continuous multiplicities as investigated through the distinction, first, between intensive properties and extensive properties and second, between space and duration, reveals the inherently temporal nature of continuous complexity. The attempt to map this dynamic form of complexity has prompted the respective development of temporal design techniques such as diagramming in folded architecture and scenario building in design. In chapter 3.2., I investigate the continuity between diagramming and scenario building, in order to continue my critique the isomorphism of folding in architecture and ecologically sustainable design. 


\subsection{Time in Architecture and Design: Mapping Dynamic Complexity}

\section{Diagrams in Architecture}

The arguments presented in folded architectural discourses have produced a renewed interest in the use of diagrams in the architectural design process. The diagram, according to architect and theorist Stan Allen (2000), is a representational technology, which has "capacities not only to take measure of the already existing complexity of the new urban field, but also intervene productively in the city today with proposals that are open and optimistic, devoted to affirmative change rather than commentary and critique" (p. 40). ${ }^{17}$ Allen explains that diagrams,

Propose an open-ended series of strategies to use within the indeterminate field of the contemporary city. They propose new scenarios, provoke unanticipated combinations and allow incremental adjustment over time. They leave space for tactical improvisation of the user in the field. Whatever coherence is attained is always a provisional stabilization of the mobile forces of the city, not set down in advance, but developed in practice. (2000, pp. 44-45)

The pragmatic capacity Allen's description grants, leads towards an understanding of the diagram as closer to a technique of strategic planning and intervention, rather than as a form of representation. This alternative reading relates to the existence of two streams of research in revival of the diagram and diagrammatic thinking in architectural discourses. DeLanda (1998, p. 30) locates the first stream of research developing from engineering and cognitive science, where diagrams have been analysed as a discipline specific form of knowledge, namely visual knowledge, which focuses on diagrams as a form of representation able to rapidly convey crucial aspects of a particular problem and in turn possible solutions. DeLanda situates the second stream of research into diagrams within the philosophy of Deleuze and its subsequent architectural interpretations, where the diagram has no intrinsic connection with representation and is concerned with the morphogenesis of form. ${ }^{18}$ The difference between these two types of diagram can be understood as related to Deleuze's 
distinction between discrete multiplicities and continuous multiplicities, where the representational diagram presents the mapping of a static or spatial form of complexity, which is opposed to the morphogenetic diagram which maps the inherently dynamic, organisation of continuous complexity. The division between these two types of diagrams is significant because, as representational diagrams are concerned with a spatial and static form of complexity, they cannot be used to map the inherently dynamic nature of continuous complexity.

The division between the operations of representational diagrams and morphogenetic diagrams however, is not the reintroduction of essentialism or a dualism of opposed and hierarchically divided absolutes. Following Deleuze (1980/1987) we can say that while representational diagrams "consist of giving form to matters, of imprisoning intensities or locking singularities into systems of resonance and redundancy... and organizing them into molar aggregates" which is "a very important, inevitable phenomenon that is beneficial in many respects and unfortunate in many others", they are unable to negotiate the irreducibility of continuous complexity like morphogenetic diagrams (p. 40).

\section{Representational Diagrams}

The incommensurability between representational and morphogenetic diagrams is not always appreciated in some architectural designs associated with folded architecture, and can instead be seen as operating in terms of a discrete form of visual knowledge. When used as a graphic tool of spatial organisation, functioning in order to reduce information such as with bubble diagrams or flow charts, the diagram can be seen operating through signs and language. This representational operation functions by ordering, dividing, juxtaposing, or stratifying components in a discrete and static space. Architectural forms that in turn "trace" such diagrams, as when the "walls" of the built 
form resemble the drawn lines of the index they are based on, can be argued as mapping a discrete form of complexity.

The situation also occurs, according to Ednie-Brown (2000, p.74), where the diagram is inserted as an intermediate step between the intention to build and the built result, such as in many designs based on computer aided animations. Although often involving impressive and uncontrolled variations which to some extent gives the design an experimental edge that is untamed by normative standards, these works in fact still fail to overcome the mechanistic model of innovation implied by representational diagram, because, by trying to suggest movement in now still form as a kind of memory or snap-shot of forces, it ironically brings about a diagramming of Bergson's concept of false or spatial time.

This criticism is maintained by Sanford Kwinter (1998), who specifically criticises "the advent of electronic gadgetry" in architecture for being caught in "fashionable neo-mechanisms" (p. 62). Kwinter argues that architects should free themselves from the mechanistic paradigm "through the relentless invention of techniques whose task is to materialise the incorporeal [map continuous complexity] by embedding everything in the flow of time" (p. 62). Kwinter argues that the diagram must be durational, not timeless but acting in time and with time, and that one misunderstands the diagram when one operates it as a template rather than as a flow. Animated moving forms map a spatial concept of time because this technology confuses movement with the space that movement passes over, a mistaken understanding which, according to Linstead and Mullarkey (2003), "is based on an illusion that space is prior to movement, that we move in a container called space" (p. 6). Thus forms which move in computer based virtual reality when built in the actual world lose the dynamism of their digital animations. Built architectural form precisely does not move, though neither is it entirely static - it endures. 
According to Michael Speaks, Lynn's argument that "architecture must move" from which he develops his practice of "animated form" (Lynn, 1997) through the use of computer modelling and animation software, is flawed because Lynn's animated forms appear to interpret the dynamic nature of a continuous multiplicity in terms of a spatial concept of time, and not in terms of the qualitative change of duration. Instead, Speaks (1998/2001) argues that Lynn should focus on "an animate form of practice" rather than "animate forms" (p. 583).

\section{Morphogenetic Diagrams}

Lynn (1993/2004) appears to anticipate Speaks' argument for an "animate form of practice" in the original publication of Folding in Architecture when he states that "rather than speak[ing] of the forms of folding autonomously, it is important to maintain a logic rather than a style of curvalinearity" (p.30) and that "diagrams should be understood as conceptual techniques that come before any particular technology" (1995a, p.17). The significance of Lynn's contribution to the practice of diagramming as "an emerging position in architecture" (Lynn, 1995a, p.18), cannot be underestimated.

Lynn (1995a) finds an example of the operation of morphogenetic diagrams in the work of Dutch architect Ben van Berkel, whose practice he situates in "a shift from representational concerns toward generative diagrams of open systems of organisation" Lynn, p. 24). Lynn (1995a) positions Van Berkel's work within this emerging territory because the "relationship between his conceptual diagrams and concrete constructions is non-linear and non-deterministic" (p. 18) such that his designs are positioned in "a dynamic rather than static space of relations" (p.19). According to Lynn, "what is promising about Van Berkel's design method is that irreducible forces are rigorously conceptualised through the use of abstract diagrams of dynamic systems of organisation" from which it follows that "these notations can not be reduced to 
mathematic or eidetic statements as time and motion are constituent to the organisation" (1995, p. 19). While Van Berkel's use of diagrammatic techniques and "protofunctional abstractions" are employed to map "forces, behaviours and relationships that are inherently dynamic and indeterminate" (Lynn, 1995a, p. 18), Van Berkel explains that,

It is not the form that has become fluid; it is the intensive intermingling of programme, events, organisational structuring and architectural formation that result in a liquid typology... [structures today] are losing their specific, separate properties and are defined more by how they relate to the organisation of the whole and how you relate to them... space opens up around you; any variety of mutations are possible, all unquantifiable, orderless, dimensionless, happening as in a fluidum. (Ben van Berkel quoted in Lynn, 1995b, p. 15)

This implies that Van Berkel's "abstract diagrams are the negotiators of concrete buildings and concepts" which while "resisting a reductive approach... neither rejects systematic thought nor retreats into the domain of naïve intuition or craft' (Lynn, 1995a, p. 21, 20). Following Lynn's analysis we can see van Berkel's operation of a morphogenetic form of diagram as mapping the inherently dynamic organisation of continuous complexity.

This shift from a representational form of practice toward an open-ended series of strategies and tactical improvisations whose concrete constructions are always a provisional stabilization of mobile forces, consequently implies a shift in design processes from one of solving clearly defined problems, to framing the right questions. As DeLanda (1998) writes, "It is only through skilful problem-posing that we can begin to think diagrammatically" (p.34).

A correlative transition toward design techniques that can map a continuous model of complexity can be seen in ecologically sustainable design through Ezio Manzini's the concept of the designer as a conceiver of scenarios. The associated practices of scenario building and the investigation of techniques of dematerialisation in product-service combinations have developed in recognition of advantage of extending 
product life-spans through the creation of enduring products that are precisely designed to be embedded in the flow of time.

\section{Product Endurance and Long-Life Design}

Sustainability in design is a temporal concept that is linked to the idea of sustainable development, in which human activity is conducted in a manner so as to maintain the environment and quality of life for future generations. The concept of sustainability developed as an alternative to throwaway culture and refers to the ability of ecosystems to maintain a form of dynamic stability which enables them to continue over long periods of time. Ecosystems are complex temporal structures involving processes operating simultaneously at varying temporal scales which develop resilience through using scale and time strategically. At large scales change happens slowly, and at smaller scale change happen faster. This way shocks to the system are responded to more quickly at smaller scales, whereas larger scales maintain the overall continuity. Such that, as Thorp (2004, p. 220) describes, having "varying rates of change within the ecosystem help sustain it."

The concept of diversity of time scales in the ecological model has also been interpreted in design in terms of product endurance. In response to the implication of a limited environment, the simple strategy of consuming less by extending the life span of products in order to need fewer of them seems a valid solution. However it was soon discovered that "making a product last long" is different from "making a longer lasting product" (van Hinte, 2004, p. 53).

Long lasting products are precisely not eternal products that resist time, but products that have a kind of life to them, products that can endure. In contrast with enduring products, eternal products according to Bruce Sterling (2004), "never lose their value, are never cheap, never antique, never collectible, always the same, they are timeless and in some profound sense dead" (p. 190). 
Product durability has been investigated through a variety of different means, involving individualisation, personalisation and through the attempted development of attachment between users and products, however these strategies, though sometimes effective, have often resulted in no more than romantic clichés or gimmicks.

The design of enduring products is more closely related to flexibility with regard to change. This has been investigated by designing products to be resilient to changes in technology and events, through the understanding of products as "ecological" assemblages of elements which can evolve at different timescales. The practice of which has been undertaken through allowing for upgradability and repair, and a move to dematerialization though product-service combinations.

The motives for the replacement of still functioning products are diverse, but in general it is simply related to the peoples' desire for well functioning and up-to-date products that can meet their changing needs. This implies that design for longevity requires anticipating upcoming possibilities and potential defects, through the creation of dynamic and flexible products which incorporate opportunities for variability and which are prepared for easy future upgrading and repair. The flexibility of enduring products is related to the flow of time and not the "flexibility" represented by curved forms or computer animations. The flexibility required by enduring products and product-service combinations implies that their design is in some way "never finished" or completely definitive. Because there is an active openness to unanticipated variations, this requires a design process that becomes closer to a form of strategic planning or scenario building, a form of abstraction that is generative rather than reductive which can be considered in relation to the function of the morphogenetic diagram in architecture. 


\section{Mapping Complexity with Scenario Building}

The techniques of scenario building or scenario planning have been productively investigated as tools for strategic planning in ecologically sustainable design discourses, particularly in response to questions of how to facilitate the transition from the current system of production towards a sustainable system, while managing the transition such that it would not also entail a social catastrophe along the way. Manzini argues that the potential to activate this transition requires designers and business, and also ordinary people to give a "strategic orientation" to their activities, and that it will require considerable planning skills: the ability to generate visions of a sustainable sociotechnical system; to organise it into a coherent system of regenerative products and services or sustainable solutions; and to communicate these visions and systems adequately so that they are recognised and appreciated by a wide enough public to render them practicable. (2003, p. 51 emphasis in the original)

Following Manzini (2003), scenario building is then a design technique that entails the development of a "set of visions" or diagrams of certain contexts in the future under certain conditions, which are employed to accommodate multiple and complex elements such that it "not only allows us to overcome the limits of intuition and more simplistic modelling, but also puts us in a better position to choose with awareness and talk our options through in a participatory planning process" (p. 136).

Manzini's characterisation of scenario building can be seen as related to the animated form of practice argued for by Speaks, who states that

Scenario planning attempts to project scenarios of possible futures... in order to access and make visible virtual paths... which are constructed from analyzing the turbulent environment itself. Scenario planning is not predictive, however, not employed to reduce disorder, thus making the right path or plan obvious. Instead, scenario planning... enhances its own flexibility and adaptability to conditions over which it has no control. (2001, p. 586)

Scenario planning can be seen as a core activity which supports a shift in the nature of design processes from one of solving clearly defined problems, to one of skilful decision making and problem-posing, that allows design more flexibility and adaptability to the complexity and uncertainty of future situations. Scenario building 
can be considered as a design technique which operates in order to map the dynamic nature of continuous complexity, and can therefore be seen as isomorphic with the techniques of morphogenetic diagramming in folded architecture.

\section{Immanence and Transcendence in Design Research}

The isomorphism investigated here between folding in architecture and ecologically sustainable design and their respective design techniques of the diagram and the scenario suggests that the two disciplines can be considered as emerging through the transition from a discrete to a continuous model of complexity. Following Deleuze's schizoanalytical method, the emergence and isomorphism of these two discourses can be seen to be informed by the divergent actualisation of an abstract machine.

We can understand the isomorphism of folded architecture and ecologically sustainable design, as a process of divergent actualisation in the same manner as that of the morphogenesis of the soap bubble and salt crystal as described in chapter 2.3.3., where a single immanent topological form is actualised in different actual forms. In the same manner that the spherical shape of a soap bubble and the cubic shape of a salt crystal do not resemble the topological form which they actualise, nor do their actual forms resemble each other, accordingly the isomorphism between folding and architecture and ecologically sustainable design must not be considered as a form of resemblance or identity. It is not the case an essence of "continuousness" somehow imposing an ideal form on a passive and receptive body from some kind of Platonic outside, but as a dynamic historical process of production whereby the discourses are defined by their response to events, how they are affected by active transformations, rather than on their possession to a set of static properties.

This follows the argument that design discourses are emergent structures produced when an intensive flow reaches certain thresholds that activate self-ordering 
as real aspects of the world, consistent with the realist commitment to capturing features of the world rather than modelling phenomena.

This implies an immanent and continuous field of design research rather than the unification of architecture and design within a transcendent totality. A unified design theory is an essentialist combination of the many and the one, whereas a continuous territory is "an organisation belonging to the many as such, which has no need whatsoever of unity in order to form a system" (Deleuze, 1968/2004a, p. 230) which instead inhabits a space characterised by "immanence of field without transcendent unification, continuity of line without global centralisation and contiguity of parts without distinct totalization" (Deleuze, 1988/1986, p. 27). Consequently, an immanent field of design research enables exchange and dialogue in a manner that does not reduce either discipline's independence.

In light of these arguments, we can investigate a design process immanent to both architecture and design, as implied by the shift from solving clearly defined problems to "thinking diagrammatically" through careful problem-posing, in a nonmetaphoric and non-essentialist way. In chapter 3.3. I investigate the nature of this immanent design process in relation to Deleuze's distinction between the axiomatic method of Royal science and the problematic method of Minor science. 


\subsection{Conceptualisation: Design Processes and the Science of Multiplicities}

The diagram and scenario are temporal design techniques that attempt to intervene in the world while respecting its irreducible complexity. This approach to negotiating complexity is, in Deleuze's terms, due to the fact that the discrete, extensive properties of actual systems cannot be used to predict the continuous structure of the intensive processes that produced it. An actual product that has reached equilibrium, steady state or stable conditions "hides" the intensive far-from-equilibrium process that gave rise to it. For example, at a human time-scale, the "static" extensive structure of a mountain hides the intensive process of tectonic folding which generates it.

A design project that is faced with this irreducible complexity, such as coaxing the transition from an unsustainable system of production to a sustainable socio-technical system, requires a design process that can "diagram" this complexity in a generative rather than reductive fashion. Such systems are described as irreducible because a complex system cannot be reduced to an aggregate of points, and any attempt to summarise the workings of a complex system in terms of fundamental, essential principles is bound to fail. As Cilliers (1998) explains "a complex system cannot be reduced to a collection of basic constituents, not because a system is not constituted by them but because too much of the relational information gets lost in the process" (p. 10). This relates to the status of prediction within complex systems. According to Bonta and Protevi (2004, p. 23), interventions which aim to control complex systems exactly cannot be made, for two reasons. First, because complex systems are sensitive to initial conditions due to the cascading affects of miniscule measurement errors. Second, because some complex systems create new presentations of behaviours as they go along. This creative aspect renders the reductive analysis and then aggregation of unit behaviours unable to account for emergent effects. 
Because complex systems are so sensitive to perturbations, even the slightest disturbance can build up to a major effect. This means that consequently, complex systems have short-term predictability and long-term unpredictability (also called deterministic chaos). A familiar example is the weather. The Meteorological Office has a very complex and detailed mathematical model of the Earth's atmosphere with which it analyses data from weather stations all over the world, which enable them to solve complex differential equations on their computer and so forecast the weather for about a week in advance. If the Earth's weather system was a closed system (discrete complexity), it follows that by simply increasing the number of weather stations and the power of the computers they should be able to extend their forecasts as long as they want. However, because the weather is a complex heterogeneous system that is driven by intensive differences, the system can spontaneously produce changes in kind or emergent effects that cannot be reduced to an aggregate of points, such that the smallest errors in the computer model quickly build up making it unpredictable in the long-term.

This sensitivity to initial conditions, discovered by Edward Lorenz with his famous butterfly effect, however presents a notion of limited unpredictability and not total chaos. I can effectively predict that the temperature in Lower Hutt on Waitangi Day 2010 will be between 10-40 degrees centigrade, meaning that the trajectory of the system (the weather pattern) frequently exhibits roughly the same behaviour but never exactly the same and never in exactly the same sequence of events. ${ }^{19}$ Consequently exact solutions cannot be attained so problems have to be resolved as Deleuze says, in "real-life operations". This implies an epistemological shift that Deleuze highlights through the distinction between problematics and axiomatics, the concerns of Minor science and Royal science respectively. This distinction in turn reveals the trajectories of two different theories of design processes. 


\section{Problematics and Axiomatics}

We can begin our analysis of the distinction that Deleuze makes between problematics and axiomatics with the investigation of Deleuze's examination of the ontology of mathematics. Deleuze's examination is not only concerned with mathematics but also refers to the reduction of ethicism to moralism, continuous to the discrete, the intensive to the extensive, abstraction to signification and immanence to transcendence, a theme investigated throughout this paper. Accordingly, Deleuze is not arguing against axiomatics and indeed claims that the translation of problematics into axiomatics is not only inevitable but scientifically necessary,

What we have, rather, are two formally different conceptions of science, and, ontologically, a single field of interaction in which royal science [axiomatics] continually appropriates the contents of vague or nomad science [problematics] while nomad science cuts the contents of royal science loose. (1980/1987, p. 367).

As Daniel W. Smith (2003b) explains, Deleuze's distinction between problematics and axiomatics or theorematics, reflects a tension within the history of mathematics that goes as far back as Greek geometry, where theorems "concern the demonstration from axioms or postulates, of the inherent properties belonging to the figure, [whereas] problems concern the construction of figures using a straightedge and a compass" (p. 415). Accordingly, theorematics and problematics concern two different forms of deduction.

In theorematics, deduction moves from axioms to theorems that are derived from it, whereas in problematics a deduction moves from the problem to the ideal accidents or events that condition the problems and form the cases that resolve it... Whereas in theorematics a figure is defined statistically, in platonic fashion, in terms of essence and its derived properties, in problematics a figure is defined dynamically by its capacity to be affected - that is by the events that befall it, cutting, projecting, folding, bending, rotating, stretching. (Smith, 2003b, p. 415)

For example, axiomatics defines a circle as an organic and fixed essence, but the morphological variations of circles ("lens-shaped”, "umbelliform”) form problematic figures that are, following Husserl, vague yet rigorous. 


\section{Vague Essences}

The axiomatics of royal science are concerned with fixed essences whereas the problematics of minor science are concerned with vague or morphological essences. Deleuze (1979, para. 17) argues that vague essences are inexact not by chance or by defect but because they are rigorously vague or anexact. Nevertheless Deleuze (1979) claims that vague essences possess a corporeality (materiality) which is not the same as sensible things (a wheel, a vase) or essences (the circle), but a corporeality that is on one hand "inseparable from processes of deformation of the event type of which it is the site, and on the other hand it is inseparable from types of qualities susceptible to greater or lesser intensities: colour, density, weight etc" (para. 18). A circle is a fixed essence, a plate or a wheel is a sensible formed thing, whereas a vague essence would be roundness, an essence that is inseparable from a process it undergoes: "roundness is simply the result, or the passage to the limit, of the process of rounding" (Deleuze, 1979, para. 19).

Rounding does not imply a fixed formal essence as described in Euclidean geometry, but a "passage to the limit, for example: the series of polygons of which the circle would be the limit" (Deleuze, 1979, para. 19; See Symmetry-Breaking Transitions chap. 2.3. and Table 3). Consequently, anexact essences are defined by dynamic events, or a symmetry-breaking transition, which Deleuze claims already implies the operation of the hand in constant correction (rectification, straightening) through operations of deformation. Deleuze's examination of vague essences implies a concept of matter as heterogeneous and dynamic, carrying implicit forms that are connected to "real life operations".

\section{Metallurgy and the Heterogeneity of Matter}

Deleuze's claim that vague essences possess a materiality that is inseparable from dynamic events, implies that matter is heterogeneous and capable of self-ordering, a 
concept that is in opposition to the notion (from the classical physics of Newton which can be traced back to Plato) of matter as simply mass, that is, as homogenous, mutable, inert and obedient. The distinction between matter as homogenous and inert, and matter as heterogeneous and carrying "implicit forms" or vague essences, also reveals two trajectories of design processes, the transcendent design process of royal science and the immanent design process of minor science.

Deleuze (1980/1987) argues, following the work of philosopher of technology Gilbert Simondon, that the axiomatic method of royal science follows the hylomorphic model (hyle meaning matter and morphic meaning form) which follows a production method that implies "both a form that organises matter and a matter prepared for the form" (p. 369) it "assumes a fixed form and a matter deemed homogenous" (p. 408). ${ }^{20}$ Deleuze argues that hylomophic model is concerned with the idea of the law or command which submits matter to a form.

This distinction between royal and minor design processes, according to Protevi (2001) can be understood as the difference between the "transcendent imposition of an architects vision of form on chaotic matter" (p.7) and the artisans approach, which follows the flow of matter by "subordinating all their operations to the sensible conditions of intuition and construction" (Deleuze \& Guattari, 1980/1987, p. 373). Deleuze (1980/1987) distinguishes between these two types of design processes as that of a difference between reproducing and following.

Reproducing implies the permanence of a fixed point of view that is external to what is reproduced: watching the flow from the bank. But following is something different from the ideal of reproduction. One is obliged to follow when one is in the search for 'singularities' of a matter, or rather of a material, and not out to discover form... when one engages in the continuous variation of variables, instead of extracting constants." (Deleuze \& Guattari, 1980/1987, p. 372)

In the hylomorphic method of royal science, the design process is "primarily conceptual or cerebral, something to be generated as a pure thought in isolation from the 
messy world of matter and energy" (DeLanda, 2001, p. 132). Once conceived, a design can be given form simply by imposing it on a material substrate, which is taken to be homogenous and receptive to the designer's wishes.

Modern steel can be seen as such a homogenous and inert material because of its standardised, docile, predictable and routine behaviour. According to James E. Gordon,

The widespread use of steel for so many purposes on the modern world is only partly due to technical causes. Steel, especially mild steel, might euphemistically be described as a material that facilitates the dilution of skills... Manufacturing processes can be broken down into many separate stages, each requiring a minimum of skill or intelligence... At a higher mental level, the design process becomes a good deal easer and more foolproof by the use of ductile, isotropic, and practically uniform material with which there is already a great deal of accumulated experience. The design of many components, such as gears and wheels, can be reduced to a routine that can be looked up in handbooks. One consequence has been that managers and accountants, rather than engineers [or designers], have become the dominant personalities in large organisations. Creative thinking is directed into rather narrow channels. Steel is archetypically, the material of big business - of large factories, railroads and so on. (James E. Gordon cited in DeLanda, 2001, p. 132)

However, Deleuze (1979) argues that in fact the homogeneity of modern steel and the routine design processes it imposes is not an essential property of the material but because the intensive capacities of modern steel have become stratified and overcoded; an effect of royal science's transcendent illusion of matter as mutable, obedient mass and "its theorematic apparatus and its organisation of work" (Deleuze \& Guattari, 1980/1987, p. 374). In fact, Deleuze (1979) claims that metal “is what compels us to think matter in continuous variation... as continuous variation of form and the continuous variation of matter itself" (para. 31). Before the advent of homogenised metals like modern steel, the ancient blacksmith had to work with metals that were always heterogeneous. One week he would get his iron from one mine, another different mine the next week, a meteor later on, meaning that each time he would have to deal with different impurities and mixtures. Consequently this demanded a "sensitivity" that could take the complexity of heterogeneous materials into account, and accordingly, a design process which could not be reduced to a routine. As Cyril Stanley Smith relates 
The craftsman [blacksmith] can compensate for differences in the qualities of his materials, for he can adjust the precise strength and application of his tools to the materials local vagaries. Conversely the constant motion of the machine requires constant materials. (Cited in DeLanda, 2001, p.136)

This presents an immanent philosophy of design where materials are not seen as inert receptacles for the imposition of form, but active participants in the design process. This implies materials that are heterogeneous, meaning that they have variable properties and idiosyncrasies that the designer must respect and make integral to the design process, which it follows cannot itself be reduced to routine. In the hylomorphic model of royal science,

operations occur between two thresholds, one of which constitutes the matter prepared for the operation, and the other the form to be incarnated... In metallurgy, on the other hand, the operations are always astride the thresholds, so that the energetic materiality overspills the prepared matter, and a qualitative deformation or transformation overspills the form. (Deleuze \& Guattari, 1980/1987, p. 410)

The thresholds Deleuze is referring to are critical points of intensity or vague essences, which by crossing (following a "line of flight") triggers a spontaneous change to occur in the structure of the material (in complexity theory terms, a bifurcation), like phase transitions such as the condensation of steam in liquid droplets, or the crystallisation of water into ice at critical points of temperature.

The minor science of the blacksmith knew about phase transitions in metals and that how one crosses these critical points is important, though this knowledge was linguistically unarticulated knowledge or "know-how". For example, once metal is melted it matters how fast it is allowed to solidify, whether it is left to air-cool slowly (annealing) or whether this processes is accelerated by plunging it into cold water (quenching). In one case you end up with a regular crystalline structure and in the other a more irregular glass like material. Similarly, the blacksmith knew that a piece of metal can be made to change its behaviour, from hard and ductile to strong and brittle, by hammering it while cold. The opposite transmutation, from hard to ductile could be 
achieved by heating the metal and then allowing it to cool slowly. Both these properties may be desirable in different tools and even in the same tool, for instance, the sword and knife requires the body to be ductile while the cutting edge must be hard. The properties of hardness or toughness, in Deleuze's terms traits of expression, and in turn their usefulness in the tool (its capacity to affect or be affected), are emergent properties that result from operations "astride" thresholds and a material containing vague essences or "implicit forms". We can now understand matter as a dynamic material capable of spontaneously generating different structures according to specific singularities which are brought out as the artisan moves the material across specific critical points by manipulating its intensity.

The concept of a dynamic and heterogeneous matter carrying implicit forms can be found in wood as well, for example where the carpenter negotiates the grain of the wood when making a piece of furniture. The carpenter "follows" the traits of expression of the material by working in partnership with its inherent properties, for example by sanding the wood with the grain. This design technique does not correspond to an axiomatic or transcendent law (there is no law that you must sand with the grain) but instead corresponds to a problematic or "designerly" way of knowing. We can now understand Deleuze when he argues that,

Simondon exposes the technological insufficiency of the matter-form model, in that it assumes a fixed form and a matter deemed homogenous. It is the idea of the law that assures the model's coherence, since laws are what submit matter to this or that form, and conversely, realize in matter a given property deduced from that form. But Simondon demonstrates that the hylomorphic model leaves many things, active and affective, by the wayside. On the one hand, to the formed and formable matter we must add an entire energetic materiality in movement, carrying singularities or haecceties that are already like implicit forms that are topological, rather than geometrical, and that combine with processes of deformation: for example, the variable undulations and torsions of the fibres guiding the operation of splitting wood. On the other hand, to the essential properties of matter deriving from the formal essence we must add variable intensive affects, now resulting from the operation, now on the contrary making it possible: for example, wood that is more or less porous, more or less elastic and resistant. At any rate it is a question of surrendering to the wood, then following where it leads by connecting operations to a materiality, instead of 
imposing a form upon matter: what one addresses is less a matter submitted to laws than a materiality possessing a nomos. One addresses less a form capable of imposing properties upon a matter than material traits of expression constituting affects. (Deleuze \& Guattari, 1980/1987, p. 408, emphasis in the original)

\section{Minor Science and Hylomorphism}

Deleuze assimilates axiomatics to royal science, the science of the royal societies and the most famous of scientists (which he links to the social axiomatic of capitalism or the State), whereas Deleuze claims that problematics have their source in minor sciences such as metallurgy, carpentry, surveying, stonecutting, and perspective. However, minor sciences are tied to the coding and formalising of royal science, which constantly tries to affect the reduction or repression of problematics to axiomatics, with the effect of "deprive[ing] them of their own model, and allow[ing] them to exist only in the capacity of 'technologies' or 'applied science'” (Deleuze 1980/1987, p. 373).

Minor sciences do not claim an autonomous power like Royal science, because

they subordinate all their operations to the sensible conditions of intuition and construction - following the flow of matter, drawing and linking up smooth space. Everything is situated in the objective zone of fluctuation that is coextensive with reality itself. However refined or rigorous, "approximate knowledge" is still dependent upon sensitive and sensible evaluations that pose more problems than they solve. (Deleuze \& Guattari, 1980/1987, p. 373, emphasis in the original)

The minor sciences are concerned with "inventing problems whose solution is tied to a whole set of collective, non-scientific activities but whose scientific solution depends, on the contrary, on royal science" (Deleuze \& Guattari, 1980/1987, p. 374, emphasis in the original). Minor sciences are linked to notions such as heterogeneity, dynamism, continuous variation, flows; that are "barred" or "banned" by royal science, which must then transpose problematic knowledge into axiomatic knowledge, "by introducing it into its theorematic apparatus and its organisation of work" (Deleuze \& Guattari, 1980/1987, p. 374, emphasis in the original). However the minor sciences can never be fully reduced to royal science, and demands its own status and rigor. When we 
maintain the primacy of royal science we cannot understand the relation between science and technology or science and practice, because minor science is not a simple technology or practice, but a scientific field in which these relationships are bought out and resolved in an entirely different way (Deleuze \& Guattari, 1980/1987, p. 367).

The distinction between the problematics of minor science and the hylomorphism of royal science implies that we must see matter in constant movement and carrying "implicit forms", potentials for self-ordering that the artisan negotiates, such that the form must be seen as suggested by matter rather than as the pure product of the mind of the architect. In minor science, the artisan must therefore "surrender" to matter, that is, follow its singularities by attending to its traits, and devise operations that bring forth those potentials to actualise the desired properties. The "architect" is blind to such traits of a complex heterogeneous matter, and despises surrendering to matter; he only sees and commands. $^{21}$

This distinction between surrender and command implies that the hylomophic model "derives less from technology or life than from a society divided into governors and governed" (Deleuze, 1980/1987, p. 369). As Simondon (quoted in Protevi, 2001) explains, "the hylomorphic schema corresponds to the knowledge of someone who stays outside the workshop and only considers what goes in and what comes out of it" (p. 8) it is the notion of the master commanding slave labour,

What the hylomorphic schema reflects in the first place is a socialised representation of work... The technical operation which imposes a form upon a passive and indeterminate matter is... essentially the operation commanded by the free man and executed by the slave. (Simondon, quoted in Protevi, 2001, p. 8)

Hylomorphic representation therefore resonates with fascist desire: the leader comes from on high to rescue the chaos of the people by his imposition of order.

\section{The Diagram, the Scenario, and the Science of Multiplicities}

The shift in design processes from mechanical representation to the diagrammatic practice in folded architecture, and from solving clearly defined problems to conceiving 
scenarios in ecologically sustainable design, can be understood as a transition from the axiomatic approach of royal science to the problematic approach of minor science. In addition, royal science and minor science imply two different models for the relationship between matter and form. The hylomorphic model of royal science presupposes matter as a homogenous mass that is obedient to laws and an inert vessel for forms imposed from the outside. The artisanal model of minor science, on the other hand, can negotiate matter in non-linear, intensive and complex conditions, where matter is capable of spontaneously creating form, drawing on its inherent tendencies and capacities to affect and be affected. This implies an intimate relationship between epistemology and ontology, where the problems posed by humans become isomorphic with the dynamic process of material systems.

Problematics presents a design process through which designers and architects can negotiate the irreducible complexity of the contemporary environment without falling victim to the transcendent illusions of essentialist and universal absolutes. The diagram and scenario can instead be seen as design processes that "overturns Platonism" through the affirmation of immanence, heterogeneity, dynamism, difference and life. 


\section{Part 4. CONCLUSION}

This part draws together the general conclusions for the research presented in this thesis, and reflects on the themes that have been investigated and addressed. It then considers the limitations of the work and makes suggestions for future research.

In response to the research presented, we should be sceptical of any brand of environmentalism or sustainable design in which social and natural harmony is based on essentialist, universal "laws of nature". Solutions to environmental issues in design discourses cannot be sought either externally to power in a transcendent position or "behind" problems of industrial production in an essentialist Nature. Instead, design ethics can be seen as the practice of developing an ethos, which considers ethical evaluations as always already folded in a multiplicity of immanent power relations which can be both repressive and enabling. This ecological aesthetics of existence becomes a never-ending activity in which tactics and problems are constantly reevaluated and adapted to changing circumstances and which seeks to invent new forms of life through the right to difference, variation and metamorphosis.

Such a design ethos requires an ethico-aesthetic design theory inherent within the shift from solving clearly defined problems to "thinking diagrammatically" through careful problem-posing. This shift in design processes can be understood as a transition from the axiomatic approach of royal science to the problematic approach of minor science, and consequently two different models for the relationship between matter and form. Rather than the hylomorphism of the axiomatic model which presupposes matter as a homogenous mass obedient to the imposition of forms from the outside, the problematic design process enables the designer to follow matter in non-linear, 
intensive and complex conditions, by creating form through partnership with matter's inherent tendencies and capacities to affect and be affected.

Problematics presents a design process through which designers and architects can negotiate the irreducible complexity of the contemporary environment without falling victim to the transcendent illusions of essentialist and universal absolutes. This intimate relationship between epistemology and ontology, whereby problems posed by designers become isomorphic with the dynamic process of material systems, enables us to understand the relation between design and issues of the environment in a different way. Through the affirmation of pragmatic experimentation, continual variation and intensive difference, Deleuze provides the philosophical concepts for an immanent and antiessentialist design ethics and aesthetics which can enable mutually beneficial conceptual exchange between architecture and design discourses.

\section{Limitations and Future Research}

It has been seen that Deleuze's philosophy provides an innovative and powerful "toolbox" of concepts that can aid the designer to intervene and experiment in the indeterminate field of the contemporary environment. However, the experimental style of Deleuze's writing, can lead to the mistake of associating his work with the more textural concerns of post-modernism and the misunderstanding of his commitment to a realist ontology. This confusion can limit the potential for interactive reflection between Deleuze's philosophy and the arguably more empirical concerns of industrial design and its relation to issues of the environment.

This research has attempted to address this problem through a selective interpretation of Deleuze's philosophy as informed by the sciences of complexity. While this strategy may have been successful to a certain degree, the use of difficult and debatable scientific concepts in turn, may have limited the extent to which this research has “clarified" Deleuze's concepts for design research. This difficulty is also 
compounded by the fact that the extension of the notion of self-organising systems to the socio-technical domain of design research is currently unable to be scientifically proven. This subsequently influences the extent to which we can claim an immanent field of design research rather than the simpler but misleading conclusion of the unification of the disciplines of architecture and design.

The parallel transition towards a problematic epistemology in design processes presented in this paper, suggests a rich conceptual site for future research. The significant history and debate regarding the relationship between design and science, for example the Design Methods Movement of the 1960's, suggests a promising reading of "the sciences of the artificial" in relation to Deleuze's distinction between axiomatics and problematics. This research path has potential to contribute to the discussion between the need for a systematic approach to design and the reduction of the sensible conditions of intuition and construction in the design process.

What we most lack is a belief in the world, we've quite lost the world, it's been taken from us. If you believe in the world you precipitate events, however inconspicuous, that elude control, you engender new space-times, however small their surface or volume. It's what you call pietas. Our ability to resist control, or our submission to it, has to be assessed at the level of our every move. We need both creativity and a people. (Deleuze, 1990, para. 13) 


\section{NOTES}

\footnotetext{
${ }^{1}$ However in order for these processes to not become essences in turn, Deleuze introduces his concept of multiplicity (see DeLanda 2002 p. 9-44 for an extended and in-depth analysis of Deleuze concepts of multiplicity)

${ }^{2}$ Foucault only attempted to systematically reconstruct his method in his last book of this period - The Archaeology of Knowledge - and so it should be noted that archaeology is not a single coherent theory from which flowed his studies of madness (Foucault 1961, 1963) and the human sciences (Foucault 1966), but the emergence of an indistinct methodology from the reworking of specific historical case studies.

${ }^{3}$ As Deleuze states in his Foucault (1986/1988) "If Foucault's interviews form an integral part of his
} work, it is because they extend the historical problematization of each of his books into the construction of the present problem, be it madness, punishment or sexuality" (p. 115). This is also in line with Deleuze's (1995) comment that a philosopher's work must be taken "as a whole" (p. 85).

${ }^{4}$ The term sciences of complexity should understood as a catch all term for the scientific researches into non-linear dynamics and complex adaptive systems beginning in the $20^{\text {th }}$ century, which "investigate the way certain material systems in the inorganic, organic and social registers attain both higher levels of internal complexity and a 'focus' of systemic behaviour without having to relay on external organising agents" (Bonta \& Protevi, 2004, p. 3).

${ }^{5}$ For a map of Deleuze's continually varying terminology see Appendix: Deleuze's Words in DeLanda, 2002a, pp. 157-180; for an in-depth glossary of Deleuze's concepts from A Thousand Plateaus see Bonta and Protevi, 2004.

${ }^{6}$ As DeLanda (2003) argues, who is also an artist as well as a philosopher "take for example his [Deleuze \& Guattari, 1980/1987, Chap. 10, 11] affirmation that all great art involves a becoming-animal of one sort or another. What would this mean if we cannot say what in reality these becomings are? (They are transformations not of organisms, like werewolves, but of the virtual multiplicities underlying the organisms). Or take the line of flight (also called the quasi-causal operator): this is the entity that builds the plane of consistency out of multiplicities. But without this definition (and the rest of the ontology) could we understand what it means to follow a line of flight in painting or music?" (Pt. III, para. 22) ${ }^{7}$ Despite the fact that this interpretation misses the point of Derrida's early essay 'force and signification' and the asignifying nature of the general text (Bonta \& Protevi, 2004, p. 7).

${ }^{8}$ See Sokal, Alan, and Bricmont, Jean. (1998). Fashionable nonsense: Postmodern intellectuals and the abuse of science. New York: Picador

${ }^{9}$ Deleuze wrote four books with Guattari, including A Thousand Plateaus part two of Capitalism and Schizophrenia (1980/1987) which I refer to extensively throughout this chapter. However, I will cite Deleuze's collaborative work with Guattari by referring just to Deleuze in the text but to both authors in the citations.

${ }^{10}$ The process of double articulation is developed from Louis Hjelmslev's linguistics but Deleuze is not suggesting that language, which is the focus of Hjelmslev's enterprise, somehow structures matter and organises life. "Despite what Hjelmslev himself may have said, the net [of Hjelmslev's apparatus] is not linguistic in scope or origin" (Deleuze \& Guattari, 1980/1987, p. 43). For a close examination of Deleuze's interpretation of Hjelmslev concepts see McClure (2001, Chap. 6.4)

${ }^{11}$ I will follow DeLanda (1992, pp. 142, 150, 157; 1997, pp. 57-70; 1999, pp. 122-128) in the next examples, so will not apply specific references in the text.

${ }^{12}$ Deleuze calls the second articulation folding (1980/1987, p. 41), however as DeLanda (1999, p. 133) points out, at this scale the proper term is cementation. However this does not undermine Deleuze's argument and in fact shows how Deleuze's concept operates at different spatio-temporal scales.

${ }^{13}$ An important difference between organic and inorganic stratification should noted whereby processes of selection in the organic sphere are not exterior and as in the case of sedimentary rock, but implicated in the organism (DNA). Also a crucial distinction between geological and organic strata is the former's tendency to accumulate around points of static equilibrium, as opposed to the latter's tendency develop form of dynamic equilibrium. (DeLanda, 1992, p.152)

${ }^{14}$ This is why DeLanda refers to Difference and repetition (1968) as Deleuze's most important book, as it is here that Deleuze develops the core philosophical concepts that he then refines and extends in his later work. The three books where Deleuze discusses the concept of the diagram is most explicitly, are concerned with a variety of subject matter; namely in his Foucault (1986/1988) where Deleuze is 
concerned with Foucault's analysis of the form of disciplinary society exemplified by the architectural form of the Panopticon; in Francis Bacon: The logic of sensation (1981/2002), Deleuze's book on the aesthetics of painter Francis Bacon, and thirdly in his collaboration work with Felix Guattari A Thousand Plateaus (1980/1987). Because Deleuze developed the concept of the diagram as a critique of representational thinking, as well as offering an original theory of the genesis of form, that there is sometimes confusion of the properly 'Deleuzian' operation of the diagram as opposed the traditional representational diagram in architectural and design processes. For as Foucault (1975/1977) reminds us, the panoptic 'dream building' was but a "diagram of a mechanism of power reduced to its ideal form; its functioning, abstracted from any obstacle, resistance or friction, must be represented as a pure architectural and optical system: it is in fact a political technology that may and must be detached from any specific use." (p. 205)

${ }^{15}$ In this description I am following DeLanda's example.

${ }^{16}$ Following Bonta and Protevi (2004, p. 17) this involves five steps: (1) Identify "important" aspects of a system's behavior, which are called it "degrees of freedom". (2) Construct a space with as many dimensions as the degrees of freedom of the system under consideration. (3) Represent each state of the system by a single point, with as many coordinates as there are dimensions. (4) Follow the movement of the point, which represents the changing states of the system as it produces a trajectory through state space, with time running as a parameter. (5) Attempt to solve the equations governing the trajectory and thereby predict the system's behavior. Following Bonta and Protevi (2004, p.20): “attractors' determine the patterns of behavior of the system, "bifurcators" are the thresholds where a system changes patterns and "symmetry-breaking events" are the transitions from one pattern to another.

${ }^{17}$ The diagram has also been the focus of great attention in relation to the ongoing "crisis of representation" in architectural theory, as a technique which can operate with greater effectiveness than the perceived inadequacy of the deconstructivist approach, which Allen (2000) argues has been "to register the instability of the system through representation of instability" (p. 5).

18 "The diagrammatic or abstract machine does not function to represent, even something real, but rather constructs a real that is yet to come, a new type of reality" (Deleuze and Guattari, 1987/1980, p. 142).

${ }^{19}$ See Mackenzie (2005b) for an extended discussion of the Lorenz attractor.

${ }^{20}$ Simondon's major works (L'individu et sa genèse physico-biologique, 1964; Du mode d'existence des objects techniques, 1969) have not been translated in English to date, except for the introduction The genesis of the individual (Simondon, 1992)

${ }^{21}$ The "architect" being used here is only an ideal figure of hylomophism and refers to the link to the Greek archē, rather than the professional title architect. 


\section{REFERENCES}

Agamben, G. (1999). Potentialities: Collected essays in philosophy (D. Heller-Roazen, Trans). Stanford: Stanford University Press.

Allen, S. (2000). Practice: Architecture, technique and representation. Amsterdam: $\mathrm{G}+\mathrm{B}$ Arts International.

Ansell-Pearson, K. \& Mullarkey, J. (Eds.). (2001). Key writings/ Henri Bergson. New York: Continuum.

Berkel, B. van., \& Bos. C. (Eds). (1998). Diagram work. ANY: Architecture New York, 23. New York, NY: Anyone Corp.

Bogue, R. (2003). Deleuze on music, painting and the arts. New York, London: Routledge

Bonta, M. \& Protevi, J. (2004). Deleuze and geophilosophy: A guide and glossary. Edinburgh: Edinburgh University Press.

Boundas, C. V. (1996). Deleuze-Bergson: An ontology of the virtual. In P. Patton (Ed.). Deleuze: A critical reader (pp. 81-103), Oxford: Blackwell.

Bové, P. (1988). Foreword: The Foucault phenomenon: The problematics of style. In G. Deleuze. Foucault (pp. vii-xl). Minneapolis: University of Minnesota Press.

Buchanan, R. (2000). The ecology of culture: Pluralism and circumstantial metaphysics. In E. Garver \& R. Buchanan (Eds.) Pluralism in theory and practice: Richard McKeon and American philosophy (pp. 135-162). Nashville: Vanderbilt University Press.

Buchanan, R. (2001). Children of the moving present: The ecology of culture and the search for causes in design. Design issues, 17(1), 67-84

Cilliers, P. (1998). Complexity and postmodernism: Understanding complex systems. London: Routledge.

Corbellini, G. (2006). Diagrams: Instructions for use. Lotus International, 127, 88-95

Darier, E. (1999a). Foucault and the environment. In E. Darier, (Ed.). Discourses of the environment (pp. 1-33). Oxford: Blackwell.

Darier, E. (1999b). Foucault against environmental ethics. In E. Darier, (Ed.). Discourses of the environment (pp. 217-240). Oxford: Blackwell.

DeLanda, M. (1992). Nonorganic life. In J. Crary \& S. Kwinter (Eds.). Zone 6: Incorporations (pp. 129-167) New York: Urzone. 
DeLanda, M. (1995, May). The geology of morals: A neomaterialist interpretation. Virtual Futures 95. Conference conducted at Warwick University, UK. Retrieved September 18, 2006 from http://www.t0.or.at/delanda/geology.htm

DeLanda, M. (1997). A thousand years of nonlinear history. New York: Zone Books/Swerve Editions.

DeLanda, M. (1998). Deleuze, diagrams, and the genesis of form. Any: Architecture New York, 23, 30-34

DeLanda, M. (1999). Immanence and transcendence in the genesis of form. In I. Buchanan (Ed.). A Deleuzian century? (pp. 119-134). Durham, NC: Duke University Press.

DeLanda, M. (2001). Philosophies of design: The case of modeling software. In J. Salazar (Ed.). Verb processing: Architecture boogazine (pp. 131-143). Barcelona: ACTAR.

DeLanda, M. (2002a). Intensive science and virtual philosophy, London, New York: Continuum.

DeLanda, M. (2002b, March). Deleuzian ontology: A sketch. New ontologies: Transdisciplinary objects. Workshop conducted at University of Illinois, USA. Retrieved September 18, 2006 from http://www2.uiuc.edu/unit/STIM/ontologies/delanda2b.pdf

DeLanda, M. (2003). 1000 years of war: CTheory interview with Manuel DeLanda. A \& M. Kroker (Eds.), Retrieved September 18, 2006 from http://www.ctheory.net/

DeLanda, M. (2004a, March). Nature Space Society. Nature Space Society. Lecture given at the Tate Modern, London, UK. Retrieved September 18, 2006 from http://www.tate.org.uk/onlineevents/archive/naturespacesociety/delanda.htm

DeLanda, M. (2004b). Materiality: Anexact and intense. In L. Spuybroek, (Ed.). NOX: Machining architecture (pp. 370-377). London: Thames \& Hudson.

DeLanda, M., Protevi, J., \& Thanem, T. (2005). Deleuzian interrogations: A conversation with Manuel DeLanda, John Protevi \& Torkild Thanem. Tamara: Journal of Critical Postmodern Organisational Science, (unpublished). Retrieved September 18, 2006 from http://www.dif-ferance.org/Delanda-Protevi.pdf

Deleuze, G. (1977). I have nothing to admit (J. Forman Trans.). Semiotext(e), 2(3), 111-116. Retrieved September 15, 2006 from http://www.its.caltech.edu/ erich/misc/nothing_to_admit

Deleuze, G. (1979). Cours Vincennes: 27/02/1979: Metal, metallurgy, music, Husserl, Simondon. Retrieved October 13, 2006 from http://www.webdeleuze.com/php/sommaire.html

Deleuze, G. (1988). Foucault (S. Hand, Trans.). Minneapolis, MN: University of Minnesota Press. (Original work published 1986) 
Deleuze, G. (Spring 1990). Control and becoming: Gilles Deleuze in conversation with Toni Negri (M. Joughin Trans.). Futur Anterieur 1. Retrieved October 23, 2006 from http://www.generation-online.org/p/fpdeleuze3.htm

Deleuze, G. (1991). Bergsonism (H. Tomlinson \& B. Habberjam, Trans.). New York: Zone Books. (Original work published 1966)

Deleuze, G. (1992). Ethology: Spinoza and us (R. Hurley Trans.). In J. Crary and S. Kwinter (Eds.), Incorporations (Vol. 6, pp. 625-633). New York: Zone Books.

Deleuze, G. (1993). The fold: Leibniz and the Baroque (T. Conley, Trans.).

Minneapolis, MN: University of Minnesota Press. (Original work published 1988)

Deleuze, G. (1995). Negotiations 1972-1990 (M. Joughin, Trans.). New York: Columbia University Press.

Deleuze, G. (1988). Spinoza: Practical philosophy (R. Hurley, Trans.). San Francisco:

City Lights Books. (Original work published 1981)

Deleuze, G. (2002). Francis Bacon: The logic of sensation. (D. W. Smith, Trans.) Minneapolis: University of Minnesota Press. (Original work published 1981)

Deleuze, G. (2004a). Difference and repetition (P. Patton, Trans.). London, New York: Continuum. (Original work published 1968)

Deleuze, G. (2004b). The logic of sense (M. Lester with C. Stivale, Trans.). London, New York: Continuum. (Original work published 1969)

Deleuze, G. \& Guattari, F. (1987). A thousand plateaus: Capitalism and schizophrenia (B. Massumi, Trans.). Minneapolis: University of Minnesota Press. (Original work published 1980)

Deleuze, G. \& Guattari, F. (1994). What is philosophy? (H. Tomlimson \& G. Burchell, Trans.). London, Ney York: Verso. (Original work published 1991)

Derrida, J. (1976). Of grammatology (G. Spivak, Trans.). Baltimore: John Hopkins University Press, 1976. (Original work published 1967)

Derrida, J. (1982). Différance. In Margins of philosophy (A. Bass, Trans. pp 3-27). Chicago: University of Chicago Press. (Original work published 1972)

Derrida, J. (2001). I'm going to have to wander all alone (L. Lawlor, Trans.). In P. Brault \& M. Nass, (Trans. and Eds.) The work of mourning (pp. 192-5). Chicago: University of Chicago Press. (Original work published 1995)

Ednie-Brown, P. (2000). The texture of diagrams: Reasonings on Greg Lynn and Francis Bacon. Daidalos, 74, 74-79

Findeli, A. (1994). Ethics, aesthetics, and design. Design Issues, 10(2), 49-68

Foucault, M. (1977). Discipline and Punish (A. Sheridan Trans.). New York: Pantheon. (Original work published 1975) 
Foucault, M. (1988a). L. D. Kritzman (Ed.). Politics, philosophy, culture: Interviews and other writings, 1977-1984 (A. Sheridan et al. Trans.). New York: Routledge.

Foucault, M. (1988b). The ethic of the care of the self as a practice of freedom: An interview with Michel Foucault conducted by Paul Fronet-Betancourt, Helmut Becker and Alfredo Gomez-Muller on January 20, 1984. In J. Bernauer and D. Rasmussen (Eds.). The final Foucault (pp. 11-20). Cambridge, Mass.: MIT Press.

Foucault, M. (1992). The use of pleasure: The history of sexuality: Volume two (R. Hurley, Trans.). London: Penguin Books. (Original work published 1984)

Foucault, M. (1998). The will to knowledge: The history of sexuality: Volume one (R. Hurley, Trans.). London: Penguin Books. (Original work published 1976)

Foucault, M. (2002a). The archaeology of knowledge (A. M. Sheridan Smith, Trans.). London, New York: Routledge. (Original work published 1969)

Foucault, M. (2002b). The subject and power. In J. D. Faubion (Ed.) Michel Foucault: The essential works, 1954-1984. Vol. 3, Power (R. Hurley et al, Trans. pp. 326348). London: Penguin Books. (Original work published 1982)

Foucault, M. (2002c). Theatrum philosophicum (D. F. Brouchard and S. Simon, Trans.). In, J. D. Faubion (Ed.) Michel Foucault: Aesthetics, method and epistemology (pp. 343-368). London: Penguin Books Ltd. (Original work published 1970)

Hayden, P. (1998). Multiplicity and becoming: The pluralist empiricism of Gilles Deleuze. New York: P. Lang.

Hays, K. M., Ingraham, C., \& Kennedy, A. (1995). Computer animisms (Two designs for the Cardiff Bay opera house). Assemblage, 26, 8-37

Hinte, E. van. (2004). Eternally yours: Time in design; Product value sustenance. Rotterdam: 010 Publishers.

Holland, E. W. (1999). Marx and philosophies of difference. In I. Buchanan, (Ed.). A Deleuzian century? Durham, London: Duke University Press, 145-161.

Krippendorf, K. (1995). On the essential contexts of artifacts or on the proposition that "design is making sense (of things)". In V. Margolin, \& R. Buchanan, (Eds.). The idea of design (156-184). Cambridge, Mass: MIT Press. (Original work published 1989)

Kwinter, S. (1998). The genealogy of models: The hammer and the song. Any: Architecture New York, 23, 57-62

Kwinter, S. (2001). Architectures of time: Toward a theory of the event in modernist culture. Cambridge, Mass.: MIT Press.

Levy, N. (1999). Foucault's unnatural ecology. In E. Darier (Ed.). Discourses of the environment (pp. 203-216). Oxford: Blackwell. 
Linstead, S., \& Mullarkey, J. (2003). Time, creativity and culture: Introducing Bergson. Culture and Organization, 9(1), 3-13

Lynn, G. (1995a). Forms of expression: The proto-functional potential of diagrams in architectural design. El Croquis, 72(1), 16-31

Lynn, G. (1995b). Conversation by modem with Ben van Berkel. El Croquis, 72(1), 615

Lynn, G. (1997). Animate form. New York: Princeton Architectural Press.

Lynn, G. (Ed.). (2004). Folding in architecture (Rev. ed.). Chichester, West Sussex; Hoboken, NJ: Wiley-Academy. (Original work published 1993).

Mackenzie, A. (2005a). Is the actual world all that must explained? The sciences and cultural theory. Cultural Values 9 (1), 101-116.

Mackenzie, A. (2005b). The problem of the attractor: A singular generality between sciences and social theory. Theory, Culture \& Society 22 (5), 45-65

Madge, P. (1997). Ecological design: A new critique. Design Issues, 16(3), 44-55

Manzini, E. (1995). Prometheus of the everyday: The ecology of the artificial and the designer's responsibility. In R. Buchanan and W. Margolin (Eds.). Discovering design: Explorations in design studies (pp. 219-243). Chicago: University of Chicago Press. (Original work published 1992)

Manzini, E. \& F. Jégou. (2003). Sustainable everyday: Scenarios of urban life (R. A. Coad, Trans.). Milan: Edizioni Ambiente.

Massumi, B. (1992) A user's guide to capitalism and schizophrenia: Deviations from Deleuze and Guattari. Cambridge, Mass: MIT Press.

Massumi, B. (1998). The diagram as technique of existence. Any: Architecture New York, 23, 42-47

Massumi, B. (2000). The parable of the cave (blind version). Retrieved September 18, 2006 from http://www.brianmassumi.com/english/interviews.html

Maturana, H. \& Varela, F. (1980). Autopoiesis and cognition: The realization of the living. In R. S. Cohen and M. W. Wartofsky (Eds.), Boston Studies in the Philosophy of Science 42. Dordecht: D. Reidel Publishing. (Original work published 1973)

McClure, B. D. (2001). Between the seen and the said Deleuze-Guattari's pragmatics of the order-word. Ph.D dissertation, Department of Philosophy, University of Warwick, UK. Retrieved September 18, 2006 from http://www.cinestatic.com/trans-mat/index.htm

Negri, A. (2004). A contribution on Foucault (D. Skinner, Trans.). Retrieved Sept. 16, 2006 from http://info.interactivist.net 
Norris, C. (1987). Derrida. Cambridge, Mass.: Harvard University Press,

Papanek, V. (1995). The green imperative: Ecology and ethics in design and architecture. London: Thames and Hudson.

Patton, P. \& Protevi, J. (2003). Introduction. In P. Patton, and J. Protevi, (Eds.). Between Deleuze and Derrida (pp. 1-14). London, New York: Continuum.

Protevi, J. (2001). Political physics: Deleuze, Derrida and the body politic. London, New York: Athalone Press.

Rabinow, P. \& Rose, N. (2003). Thoughts on the concept of biopower today. Retrieved Sept. 16, 2006 from http://www.lse.ac.uk/collections/sociology/pdf/RabinowandRoseBiopowerToday03.pdf

Rajchman, J. (2004). Out of the fold. In G. Lynn (Ed.). Folding in architecture (Rev. ed. pp. 77-79). Chichester, West Sussex; Hoboken, NJ: Wiley-Academy. (Original work published 1993).

Simondon, G. (1992). The genesis of the individual (M. Cohen and S. Kwinter Trans.). In J. Crary and S. Kwinter (Eds.), Incorporations (Vol. 6, pp. 297-319). New York: Zone Books.

Simon, H. A. (1996). The sciences of the artificial (3rd ed.). Cambridge, Mass: MIT Press. (Original work published 1969)

Smith, D. W. (2003a). Deleuze and Derrida, immanence and transcendence: Two directions in recent French thought. In P. Patton, and J. Protevi, (Eds.). Between Deleuze and Derrida (pp. 46-66). London, New York: Continuum.

Smith, D. W. (2003b). Mathematics and the theory of multiplicities: Badiou and Deleuze revisited. The Southern Journal of Philosophy XLI, 411-449

Speaks, M. (2001). It's out there... The formal limits of the American avant-garde. In O. Eliasson. P. Weibel (Ed.) Olafur Eliasson: Surroundings surrounded: Essays on space and science (pp. 572-586). Graz, Austria: Neue Galerie am Landesmuseum Joanneum; Cambridge, MA: MIT Press, 2001. (Original work published 1998)

Sterling, B. (2004). Untitled. In E. van Hinte. Eternally yours: Time in design; Product value sustenance (pp. 178-194). Rotterdam: 010 Publishers.

Thorp, A. (2004). Time in design. In E. van Hinte. Eternally yours: Time in design; Product value sustenance (pp. 214-238). Rotterdam: 010 Publishers.

Whitely, N. (1999). Utility, design principles and the ethical tradition. In J. Attfield (Ed.). Utility reassessed: The role of ethics in the practice of design (pp. 190202). Manchester: Manchester University Press. 